\title{
In situ food-borne pathogen sensors in a nanoconfined space by surface enhanced Raman scattering
}

\author{
Lu-Lu Qu ${ }^{1}$ Yi-Lun Ying ${ }^{2} \cdot$ Ru-Jia Yu ${ }^{2}$ (i) $\cdot$ Yi-Tao Long ${ }^{2}$ \\ Received: 31 January 2021 / Accepted: 13 May 2021 / Published online: 27 May 2021 \\ (C) The Author(s), under exclusive licence to Springer-Verlag GmbH Austria, part of Springer Nature 2021
}

\begin{abstract}
The incidence of disease arising from food-borne pathogens is increasing continuously and has become a global public health problem. Rapid and accurate identification of food-borne pathogens is essential for adopting disease intervention strategies and controlling the spread of epidemics. Surface-enhanced Raman spectroscopy (SERS) has attracted increasing interest due to the attractive features including simplicity, rapid measurement, and high sensitivity. It can be used for rapid in situ sensing of single and multicomponent samples within the nanostructure-based confined space by providing molecular fingerprint information and has been demonstrated to be an effective detection strategy for pathogens. This article aims to review the application of SERS to the rapid sensing of food-borne pathogens in food matrices. The mechanisms and advantages of SERS, and detection strategies are briefly discussed. The latest progress on the use of SERS for rapid detection of food-borne bacteria and viruses is considered, including both the labeled and label-free detection strategies. In closing, according to the current situation regarding detection of food-borne pathogens, the review highlights the challenges faced by SERS and the prospects for new applications in food safety.
\end{abstract}

Keywords Bacterium $\cdot$ Virus detection $\cdot$ Food pathogens $\cdot$ Food analysis $\cdot$ SERS $\cdot$ Nanoconfined space $\cdot$ Nanostructures

\section{Introduction}

The outbreak of novel coronavirus (COVID-19) pneumonia associated with high morbidity and mortality has caused everincreasing attention and public panic throughout the world [1, 2].. COVID-19 has been detected in various frozen foods, particularly in their packaging and the storage environments [3-5], which makes food safety an important issue of global concern nowadays. In fact, the presence of food-borne pathogenic microorganisms during the processes of food production and supply would cause food contamination, spoilage, and deterioration, thus resulting in nausea, vomiting, stomach

Lu-Lu Qu

luluqu@jsnu.edu.cn

Ru-Jia Yu

yurujia@nju.edu.cn

1 School of Chemistry and Materials Science, Jiangsu Normal University, 221116 Xuzhou, People's Republic of China

2 State Key Laboratory of Analytical Chemistry for Life Science, School of Chemistry and Chemical Engineering, Nanjing University, Nanjing 210023, People's Republic of China pain etc., and in serious cases, organ damage [6, 7]. For example, after Shigella enters into human intestine, it can destroy the intestinal mucosa due to the dual effects of endotoxins and exotoxins and cause human intestinal disease $[8$, 9]. Therefore, it is vital to access a sensitive and selective technique for rapid monitoring of food pathogens, including bacteria and viruses, to protect people against potential health risks.

Conventional methods for detection of pathogens mainly include culture analysis and metabolic tests $[10,11]$, which are known as the gold standards for bacterial identification. However, the detection process may take several days to a week that could hardly be adaptable in rapid emergency events. Current methods for pathogen detection generally employ the nucleic acid-based polymerase chain reaction (PCR) and enzyme-linked immunoassay, showing the advantages of high specificity, high sensitivity, and ease of observation [12-14]. Although these methods can produce results within a few hours, they require complex steps, time-consuming sample pretreatments, and skilled personnel.

The demand for rapid and cost-effective pathogen diagnostic methods has prompted researchers to focus on the development of real-time biosensing platforms [15-17]. Among the 
various biosensor technologies, surface-enhanced Raman spectroscopy (SERS) as a vibrational spectroscopic technique has attracted increasing attention due to its prominent characteristics such as high sensitivity, low water interference, short detection time, and the rapid, in situ, and noninvasive capabilities [18-21]. The SERS effect mainly derives from the local electromagnetic field enhancement generated on or near the surface of coinage-metal nanostructures, and the resulting chemical interaction between the nanostructure surface and the adsorbed molecules [22, 23]. This interaction-based construction of SERS-active nanomaterials is one of the most important prerequisites for expanding SERS applications in biological analysis. It has been shown that only substrates at the nano-scale can generate high SERS enhancements that are also known as the enhancement of nanoconfined space provided by the diversified nanostructures. The nanoconfined space refers to nanoscale geometry of the structure surface or the gaps between, where the plasmon resonance or the electron oscillate occurs. The shape, size, composition, and particle spacing of metallic nanostructures are the key factors that affect surface plasmon resonance (SPR) and the electromagnetic fields [24-27], which need to be carefully designed to ensure SERS enhancement and excellent signal reproducibility. The commonly used substrates for biological applications mainly include colloidal nanoparticles, surfaces modified with nanostructures, and colloidal SERS tags [28-31]. Colloids and surface substrates are generally designed to measure the inherent SERS signal of the analytes, while SERS nanoparticle tags are usually combined with targeting ligands such as aptamers and antibodies for detection.

The research on SERS detection and differentiation of pathogens can be dated to 1998, when Efrima et al. [32] obtained the SERS spectra of Escherichia coli with colloidal Ag nanoparticles deposited on the outer membrane of Escherichia coli. Since then, the application of SERS technique in pathogen identification and classification has blossomed rapidly [24, 33-36]. The combination of handheld portable Raman spectrometers with nanostructured substrates provides strategies for rapid identification of pathogens in a nanoconfined space, though there are still some challenges such as batch-to-batch consistency and multiple analysis [37-39]. Nowadays, SERS can be used for the detection of single cell bacteria or a single spore [40, 41]. In this review paper, we focus on the latest progress in rapid detection of food-borne pathogenic microorganisms by SERS. The mechanisms and sensing strategies for SERS detection of pathogens are firstly discussed, followed by the details on the SERS nanostructures. Finally, we discuss the challenges and opportunities in developing next-generation SERS nanostructures for pathogens sensing in real food samples.

\section{SERS mechanisms and advantages}

Since the discovery of SERS, the enhancement mechanism has become a hot research topic. Two primary mechanistic models have been proposed, namely, electromagnetic (EM) field enhancement and chemical enhancement (CE) [22, 23, 42]. EM enhancement makes a major contribution to the SERS phenomenon. With a certain frequency EM radiation incident on noble metal nanostructures, the conduction electrons oscillate collectively under the action of the radiation electric field, which is termed surface plasmon resonance (SPR) [43]. The surface of the nanostructure will generate a redistribution of the local field and a great increase in the EM field. The Raman mode of molecules confined in these EM fields will be greatly enhanced. Therefore, the EM has a longrange effect because molecules on or near the metal surface experience the enormous field enhancement. In CE, the metal and adsorbed molecules generate charge transfer states, which increases the possibility of Raman transitions by providing resonance excitation [44]. CE is position-specific and analyte-dependent and provides one or two orders of magnitude increase in Raman signal intensity. The analyte molecule should be directly adsorbed to the metal surface to allow a charge transfer state. Due to the complex charge transfer process, many factors can influence charge transfer, such as the nature of the analyte molecules, metal nanostructures, excitation wavelengths, and molecular vibration modes. It can be concluded that the EM enhancement emphasizes the role of the nano-substrate to provide a long-distance EM field, which depends on the inherent characteristics of the nano-substrate. However, CE can be achieved by changing the scattering cross section of the analyte attached to the metal surface. Thus, the degree of enhancement depends on the chemical characteristics of the analytes.

One of the biggest challenges in SERS is related to the activity of the molecular system being studied. Theoretically, all molecules with changeable polarizability could produce SERS, but not all molecules are good SERS probes $[45,46]$. SERS activity mainly depends on three factors: the electromagnetic field generated by the plasmonic nanostructure used as an optical intensifier, the intrinsic Raman properties of the molecule, and the affinity between molecule and plasmonic surface. The first factor, the electromagnetic field or the local surface plasmon resonance (LSPR), is the basis of SERS, and the other two dominate the sensitivity in different systems. Therefore, they are all related to the bacteria detection.

Compared with other pathogen detection methods, SERS detection platform has clear advantages. For instance, compared with fluorescence, the instantaneous features of Raman Scattering enable the excitation energy relax at a faster rate $[47,48]$, inducing a more stable SERS signals which is resistant to photodegradation or photobleaching. The peak width 
of the Raman signal is about $1-2 \mathrm{~nm}$, which is $10-100$ times narrower than the fluorescence emission of traditional organic dyes or quantum dots [49], hence the Raman signal is more conducive to multi-component analysis. In addition, unlike infrared spectroscopy, water exhibits negligible Raman scattering [50] which is beneficial for biological sensing.

\section{SERS detection strategies for pathogens}

There are two SERS configurations for bacteria and virus detection, namely unlabeled or labeled SERS, as shown in Scheme 1. In label-free detection, bacterial cells and viruses or their metabolites can be directly introduced onto the nanostructures surface. The intrinsic Raman spectra of the biomolecules in the nanoconfined space can be directly measured to identify the samples. While in labeled detection, Raman reporter molecules are introduced to generate SERS signals. To facilitate target capture and enable the specific detection, ligands such as antibodies, aptamers, or related molecules are typically immobilized on the nanostructures surface. The differences in Raman spectral before and after capture of the targets can be used to identify the targets. For example, Au nanoparticles (AuNPs) immobilized with Raman reporter can be used as SERS active substrate. A core-shell nanostructure can then be formed by covering this structure with another layer of medium such as silica or polymer, where the shell may be decorated with capture molecules. Therefore, the target bacteria can be captured and detected by this elaborate design of sandwich structure.

\section{Detection of food-borne bacteria}

SERS-based technology has long been applied for the detection of food-borne bacteria, which serves as a rapid alternative for evaluation of food safety. These methods mainly include the confined nanostructures-based detection of bacteria, such as Escherichia coli, Staphylococcus aureus, and Salmonella typhimurium, which are summarized in Table 1.

\section{Label-free detection of bacteria}

Bacteria are generally in large volumes, contain complex chemical components including proteins, nucleic acids, enzymes, and various inorganic and organic substances [50, 68].. Although SERS spectrum owns the fingerprint characteristics, the complex spectral characteristics of bacteria make it difficult to identify specific targets in some cases. Consequently, chemometrics is employed to assist in the qualitative and quantitative analysis of SERS spectrochemical measurements. Multivariate data analysis including principal component analysis (PCA) and partial least squares (PLS) regression are the commonly used statistical methods [34, 69]. PCA is a primary mathematical method to reduce the data dimensions by identifying correlations among a set of variables and then projecting the original set of variables into a new set of uncorrelated variables called principal components. PLS uses a linear combination of the predictor variables to project the original data to a new set of coordinates to generate a positive/negative prediction. Thus, PCA analysis is generally employed for the classification of bacteria with given features, like Gram stain results.

Label-free SERS detection is generally employed to directly obtain SERS spectra of bacterial cells without the need for synthesis of Raman dyes and SERS tags. This method has the advantages of simplicity and convenience.

\section{Detection of bacterial cells}

There are typically three strategies for label-free detection of bacterial cells in SERS: mixing the bacteria with colloidal nanoparticles to induce aggregation, placing the entire bacteria cell directly on the solid SERS substrate, and assembling colloidal nanoparticles onto the bacteria surface directly. Silver
Lable-free SERS detection

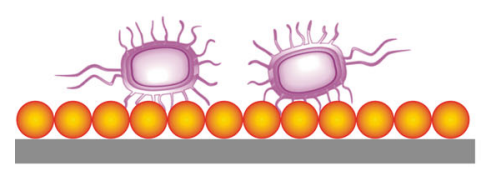

Placing bacteria on substrates
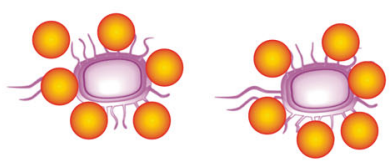

Assemble nanoparticles on bacteria
Labeled SERS detection

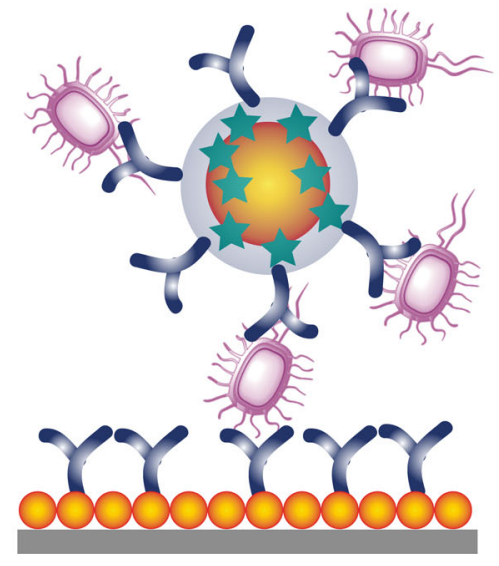

Nanoparticle

Raman reporter

Pathogen

Antibody

Outer shell

Scheme 1 Typical SERS detection configurations: label-free detection and labeled detection 
Table 1 Food-borne bacteria detected by SERS

\begin{tabular}{|c|c|c|c|c|}
\hline Food-borne bacteria & Detection strategy & SERS Substrates & LOD & Ref. \\
\hline \multirow[t]{11}{*}{ Escherichia coli } & \multirow[t]{7}{*}{ Label-free } & AgNPs & Single cells & {$[51]$} \\
\hline & & Au@AgNP-coated mussel shell & - & {$[52]$} \\
\hline & & $\mathrm{HfTe}_{2}$-Au nanocomposites & $10 \mathrm{CFU} \mathrm{mL} \mathrm{m}^{-1}$ & {$[53]$} \\
\hline & & Black phosphorus-Au-based filter paper & $10^{7} \mathrm{CFU} \mathrm{mL} \mathrm{m}^{-1}$ & {$[54]$} \\
\hline & & In situ synthesis of AgNPs on cell & $2.5 \times 10^{2}$ cells $\mathrm{mL}$ & [35] \\
\hline & & Vancomycin functionalized AgNR & $10^{2} \mathrm{CFU} \mathrm{mL} \mathrm{L}^{-1}$ & [55] \\
\hline & & Nanoplate-bacteria-nanorod supercrystals & $10^{3} \mathrm{CFU} \mathrm{mL}^{-1}$ & {$[56]$} \\
\hline & \multirow[t]{4}{*}{ Labeled } & AuNPs and $\mathrm{Fe}_{3} \mathrm{O}_{4}$ & $10 \mathrm{CFU} \mathrm{mL}^{-1}$ & {$[57]$} \\
\hline & & AuNPs and $\mathrm{Fe}_{3} \mathrm{O}_{4}$ & $10 \mathrm{CFU} \mathrm{mL}^{-1}$ & [58] \\
\hline & & AuNRs and $\mathrm{Fe}_{3} \mathrm{O}_{4}$ & $10 \mathrm{CFU} \mathrm{mL}^{-1}$ & [59] \\
\hline & & Gold nanobones \& $\mathrm{Fe}_{3} \mathrm{O}_{4}$ & $10 \mathrm{CFU} \mathrm{mL} \mathrm{L}^{-1}$ & {$[60]$} \\
\hline \multirow[t]{7}{*}{ Staphylococcus aureus } & \multirow[t]{2}{*}{ Label-free } & $\mathrm{HfTe}_{2}$-Au nanocomposites & $10 \mathrm{CFU} \mathrm{mL} \mathrm{m}^{-1}$ & {$[53]$} \\
\hline & & Black phosphorus-Au-based filter paper & $10^{7} \mathrm{CFU} / \mathrm{mL}$ & [54] \\
\hline & \multirow[t]{5}{*}{ Labeled } & AuNPs and $\mathrm{Fe}_{3} \mathrm{O}_{4}$ & $25 \mathrm{CFU} \mathrm{mL} \mathrm{m}^{-1}$ & [58] \\
\hline & & AuNPs & $10^{1} \mathrm{CFU} \mathrm{mL}^{-1}$ & [61] \\
\hline & & AuNPs and $\mathrm{Fe}_{3} \mathrm{O}_{4}$ magnetic AuNPs & $35 \mathrm{CFU} \mathrm{mL} \mathrm{m}^{-1}$ & {$[62]$} \\
\hline & & $\begin{array}{l}\text { Ag-coated magnetic nanoparticles and } \\
\text { AuNR-DTNB@A-DTNB core-shell plasmonic NPs }\end{array}$ & 10 cells $\mathrm{mL}^{-1}$ & [63] \\
\hline & & AuNPs/PDMS \& Au-Ag core-shell nanoflowers & $13 \mathrm{CFU} \mathrm{mL}{ }^{-1}$ & [64] \\
\hline \multirow[t]{6}{*}{ Salmonella typhimurium } & \multirow[t]{2}{*}{ Label-free } & $\mathrm{HfTe}_{2}-\mathrm{Au}$ nanocomposites & $10 \mathrm{CFU} \mathrm{mL} \mathrm{m}^{-1}$ & [53] \\
\hline & & Vancomycin functionalized AgNR & $10^{2} \mathrm{CFU} \mathrm{mL} \mathrm{m}^{-1}$ & {$[55]$} \\
\hline & \multirow[t]{4}{*}{ Labeled } & AuNPs & $10^{3} \mathrm{CFU} \mathrm{mL}^{-1}$ & {$[62]$} \\
\hline & & AuNPs and $\mathrm{Fe}_{3} \mathrm{O}_{4}$ magnetic AuNPs & $15 \mathrm{CFU} \mathrm{mL}^{-1}$ & {$[65]$} \\
\hline & & AuNRs and $\mathrm{Fe}_{3} \mathrm{O}_{4}$ & $8 \mathrm{CFU} \mathrm{mL}{ }^{-1}$ & {$[59]$} \\
\hline & & AuNPs/PDMS & $27 \mathrm{CFU} \mathrm{mL}^{-1}$ & [66] \\
\hline Staphylococcus epidermidis & Label-free & Vancomycin functionalized AgNR & $10^{2} \mathrm{CFU} \mathrm{mL} \mathrm{m}^{-1}$ & {$[55]$} \\
\hline \multirow[t]{2}{*}{ Listeria monocytogenes } & \multirow[t]{2}{*}{ Label-free } & $\mathrm{HfTe}_{2}$-AuNPs & $10 \mathrm{CFU} \mathrm{mL} \mathrm{L}^{-1}$ & [53] \\
\hline & & Black phosphorus-Au-based filter paper & $10^{7} \mathrm{CFU} \mathrm{mL}^{-1}$ & {$[54]$} \\
\hline Staphylococcus xylosus & Label-free & Nanoplate-bacteria-nanorod supercrystals & $10^{3} \mathrm{CFU} \mathrm{mL}^{-1}$ & {$[56]$} \\
\hline \multirow[t]{3}{*}{ Bacillus } & \multirow[t]{3}{*}{ Label-free } & Silver film over nanosphere & $2.6 \times 10^{3}$ spores & [67] \\
\hline & & Silver colloids & $29.9 \mathrm{nM}$ & [37] \\
\hline & & Colloid meso-droplets on superhydrophobic wires & 18 spores & \\
\hline Vibrio parahaemolyticus & Labeled & AuNPs/PDMS & $18 \mathrm{CFU} \mathrm{mL}^{-1}$ & {$[66]$} \\
\hline
\end{tabular}

nanoparticles (AgNPs) were initially employed as a SERS substrate to rapidly distinguish Staphylococcus epidermidis, Enterococcus faecelis, Escherichia coli O157:H7, and Listeria monocytogenes in water and food [51]. Subsequently, a series of nanostructures such as Au@Ag nanoparticle-coated mussel shell (Fig. 1a, b) [52], HfTe $\mathrm{H}_{2} \mathrm{Au}$ nanocomposites [53], and black phosphorus-Au filter paper [54] were fabricated for the rapid detection of Escherichia coli, Staphylococcus aureus, Pseudomonas aeruginosa, and Listeria monocytogenes. To achieve higher sensitivity and improved reproducibility, AgNPs were in situ synthesized on the bacterial cell surface for label-free SERS detection. For example, living bacteria in drinking water could be detected by in situ coating bacterial cell wall with AgNPs [35].
The enhancement of the specific Raman signal via this method was nearly 30 -fold greater than that for a simple mixed colloid-bacterial suspension.

Compared with nanostructures (typical dimensions 10$100 \mathrm{~nm}$ ), most large bacteria are typically with diameter of $0.5-1 \mu \mathrm{m}$ and length of $1-2 \mu \mathrm{m}$. This mismatch in size hampers contact between bacteria and nanostructures [70, 71]. The measurement principles of SERS distance dependence indicate that the intensity increases with the reducing surface-totarget distance $\mathrm{R}$. Considering the field enhancement decays with $\mathrm{R}^{-3}$, the whole distance dependence should scale with $\mathrm{R}^{-12}$ followed with $\mathrm{E}^{4}$ approximation. Experimentally, the distance dependance should be $\mathrm{R}^{-10}$ by including a rectified $\mathrm{R}^{2}$ due to the increased surface area scaling, that is the shell of 

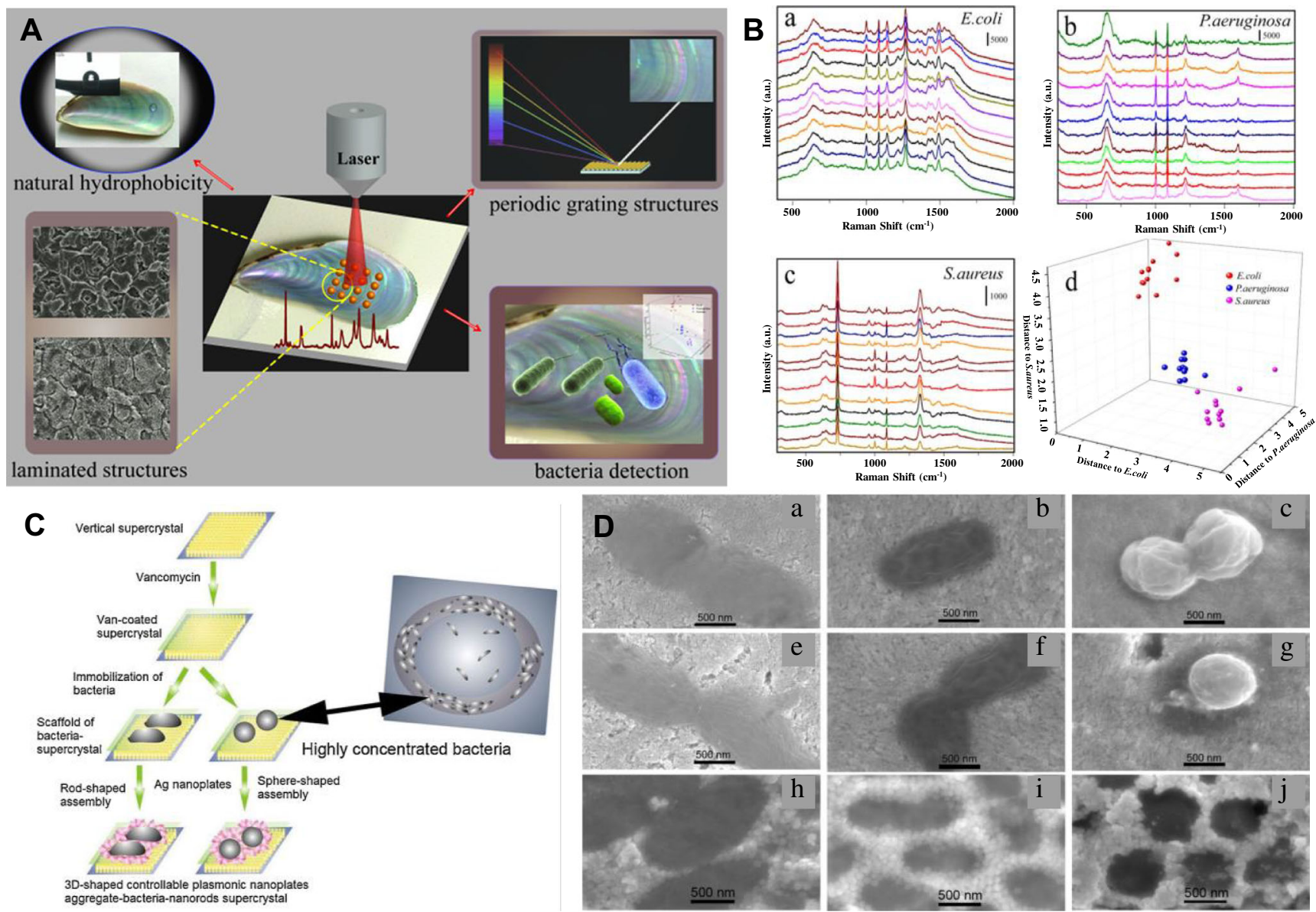

Fig. 1 a, b The rapid detection of Escherichia coli, Staphylococcus aureus, and Pseudomonas aeruginosa by using Au@Ag nanoparticlecoated mussel shell. Reprinted with permission from ref. 52. c The scheme for preparing 3D-shaped controllable nanostructures for the

detection of bacteria. d SEM images of Escherichia coli, S. enterica, and Staphylococcus xylosus on various nanostructures. Reprinted with permission from ref. 56

targets at the increased distance from substrate surface [72]. Hence, reducing the distance between the bacterium and the nanostructure would greatly improve the detection sensitivity of the SERS-active substrates. Both chemical bonding and manipulation through physical forces can be the right solutions $[23,73]$. Given that the nuclei of lipopolysaccharide molecules of bacteria are phosphate- and carboxylate-rich, the surface of the bacterial membrane is negatively charged. The synthesized positively charged Au nanorods can be adsorbed onto the bacteria surface via electrostatic adsorption. Using such an approach and with the aid of multivariate analysis, four types of Pseudomonas isolated from rotten chicken were classified [74]. Vancomycin, a well-known glycopeptide antibiotic capable of strongly interacting with the bacterial cell wall via hydrogen bonds [55], was used to modify SERSactive substrates and subsequently capture the bacteria. An atomic force microscopy (AFM) image of the bacteria on vancomycin modified substrates indicated the deformation of the bacterial cell, which suggested that the bacteria were bonded more closely to the SERS-active substrates. The corresponding results demonstrated that the SERS intensity of the bacteria increased at least 1000 times as a result of decreasing the distance [75]. Similarly, a 3D bio-inorganic scaffold-based confined nanostructure was constructed for the detection of Gram-positive and Gram-negative bacteria, including Escherichia coli, Salmonella enterica, and Staphylococcus xylosus [56]. This method allowed the detection of Scherichia coli and Staphylococcus xylosus with LODs of $10^{3} \mathrm{CFU} / \mathrm{mL}$ and $10^{2} \mathrm{CFU} / \mathrm{mL}$, respectively (Fig. 1c, d). PCA analysis of the single and mix bacteria samples was further implemented for the discrimination of different kinds of bacteria. The detection of bacteria in soft drinks demonstrated the feasibility of this method in quality control analysis of foods and drinks. Another significant method to improve the detection sensitivity is to combine SERS with sample pre-concentration whereby a maximus number of bacteria are captured onto a large fixed surface area such as magnetic nanoparticles (MNPs). For example, magnetic-plasmonic nanoparticles were fabricated and used for the enrichment of bacteria by applying an external magnetic field [76]. 
.The above studies have demonstrated that SERS can be used for the identification and classification of bacteria cells. However, none of the label-free bacteria detection methods have considered the real-world scenarios whereby large numbers of bacterial species often exist together in a biological sample, along with bacteria from different serotypes and strains. Although chemometric analysis of SERS signals is applied to distinguish bacteria present in species, strains, and serotypes, it has limitations in the presence of mixtures of different bacteria [77-79]. When two or more kinds of bacteria are combined, the spectrum of the mixture sometimes shows spectral characteristics of the individual bacteria, because the SERS process relates to the vibrational modes of the chemical bonds.

\section{Detection of bacterial metabolites}

As mentioned above, the Raman signals of bacteria originate from cell membranes with similar chemical structures and composition for most bacterial species. Thus, it is still challenging to distinguish closely related species, especially in bacterial mixtures $[80,81]$. In addition, cells should be washed repeatedly and resuspended in pure water to avoid the potential interference of the residual matrix or buffer. The interruption of osmotic balance would result in bacterial cell disruption, which may affect the repeatability of analysis due to inconsistent sample composition. For these reasons, the detection of whole bacterial cells via Raman method is still challenging. The indirect sensing of bacteria thus becomes an alternative method, which is mainly performed by identifying specific markers released by organisms in the matrix fluid. Calcium dipicolinate (CaDPA), an important biomarker for bacillus spores, was detected via its SERS spectra on Ag film over nanosphere (AgFON) substrates. The capability of this approach for bacillus spores sensing was demonstrated with LOD of $2.6 \times 10^{3}$, which was lower than the infectious dose level of $10^{4}$ spores for anthrax (Fig. 2a) [67]. In addition, the SERS spectra of dipicolinic acid (DPA) extracted from spores of Bacillus was also obtained using nanoparticles. Cowcher et al. demonstrated that colloidal nanoparticles as SERS substrates could be used for rapid detection and quantification of the DPA at the $5 \mathrm{ppb}(29.9 \mathrm{nM})$ level [37]. Cheung et al. performed SERS measurements of $<1 \mu \mathrm{L}$ of analyte/colloid meso-droplets on superhydrophobic wires with hydrophilic tips, which enabled the detection of DPA at $10^{-6} \mathrm{~mol} \mathrm{dm}^{-3}$. This sensing performance is approximately to 18 spores, a level which is greatly below the infectious dose and nearly two orders of magnitude more sensitive than previous methods [83]. Based on the loading of Au nanostars on a flat filter, Guo et al. developed user-friendly SERS devices for measurement of gaseous metabolites of bacteria (Fig. 2b, c). The impressive performance of such devices for the detection of gaseous metabolites of common foodborne bacteria such as
Escherichia coli, Staphylococcus aureus, and Pseudomonas aeruginosa from inoculated samples achieved extremely high sensitivity. The approach further enabled the detection of spoiled food at an early stage and tracking of the degree of food spoilage in real-time [82].

\section{Detection of bacterial DNA}

Instead of detection and differentiation of the bacterial whole cell, the bacterial gene (DNA or RNA) is an attractive alternative given that the genes could reflect the unique genetic information of bacteria species, strains, and serotypes [84-86]. The specificity of the SERS-based gene probe relies on its hybridization with complementary target bacterial gene sequence, where SERS is used to characterize the change before and after such hybridization [87-90]. The facile synthesis of genetic sequences and their relatively small size confer unique advantages compared to whole cell detection [91-95].

.The SERS-based DNA gene probe was first reported by Vo-Dinh et al. [96] in 1994 and was applied for the detection of DNA biotargets via hybridization to complementary DNA sequences. During the last decades, numbers of SERS-based DNA sensing assays have been developed to detect bacterial genomes. Typically, MNPs have been fabricated for separation of the DNA strands. Following the binding of target DNA, a short synthetic ssDNA with specific dye modification was hybridized, which served as label for SERS sensing. The PCR product of the bacterium Mycoplasma mycoides subspecies mycoides small colony type (MmmSC) was amplified and then detected by SERS. The multiplexing capability of the SERS method has been further verified by simultaneous detection of three independent PCR products with different dyes modification [97]. Van Lierop et al. [98] reported a separation-free SERS method by employing a well-designed SERS primer, which showed a distinct enhancement in the SERS intensity in the presence of target DNA. The presence of specific bacterial DNA from Staphylococcus epidermidis was amplified by PCR and then detected by SERS. Multiplexing bacterial DNA detection was achieved by Kang et al. [99] via an Au particle-on-wire platform. Au nanowire immobilized with probe DNA and Au nanoparticle linked with reporter DNA was employed in such platform. Both the probe and reporter DNA were complementary to the target DNA, forming a sandwich hybridization of reporter-target-probe DNAs (Fig. 3). The nanoconfined space for SERS enhancement could be created with the coupling between Au nanowire and Au nanoparticle. Thus, only after the formation of sandwich hybridization, the Raman dye on the reported DNA could be within this confined space, whereafter SERS detection was performed. Using this SERS platform, PCR products of the 4 different bacteria from 7 clinical isolates (Enterococcus faecium, 2 isolates; 

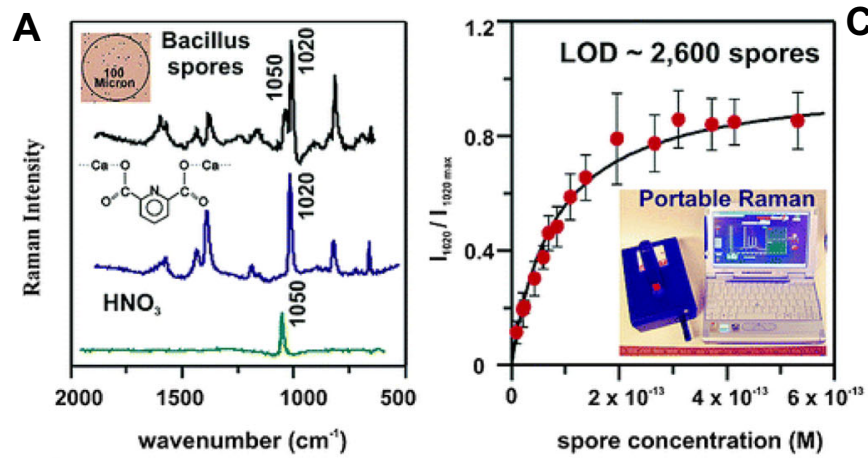

B

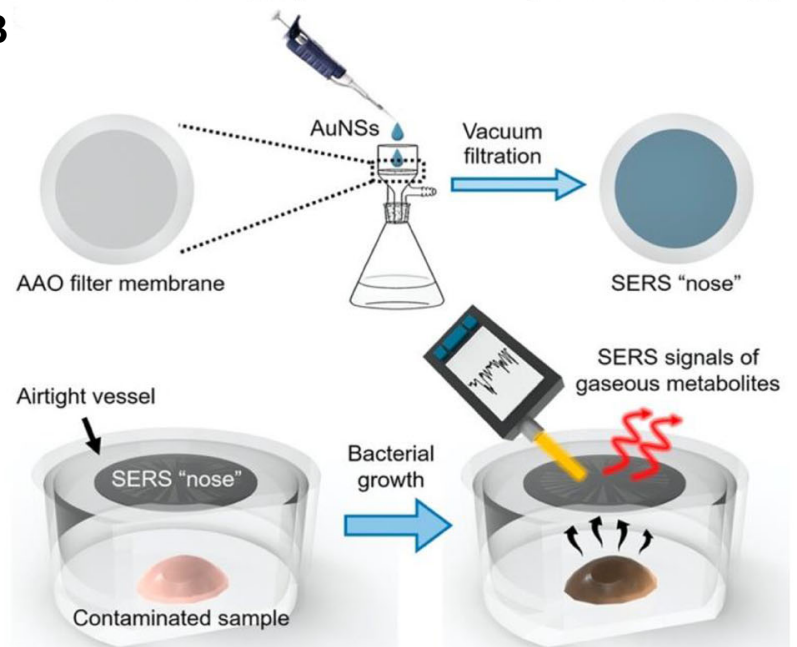

Fig. 2 A SERS detection of CaDPA from B. subtilis spores. Reprinted with permission from ref. 67. B Schematic for monitoring of gas metabolites from contaminated samples. C Photos of a SERS "nose" and pork inoculated with $\mathrm{Au}$ nanostars-coated flat filter and bacteria. $\mathrm{b}$
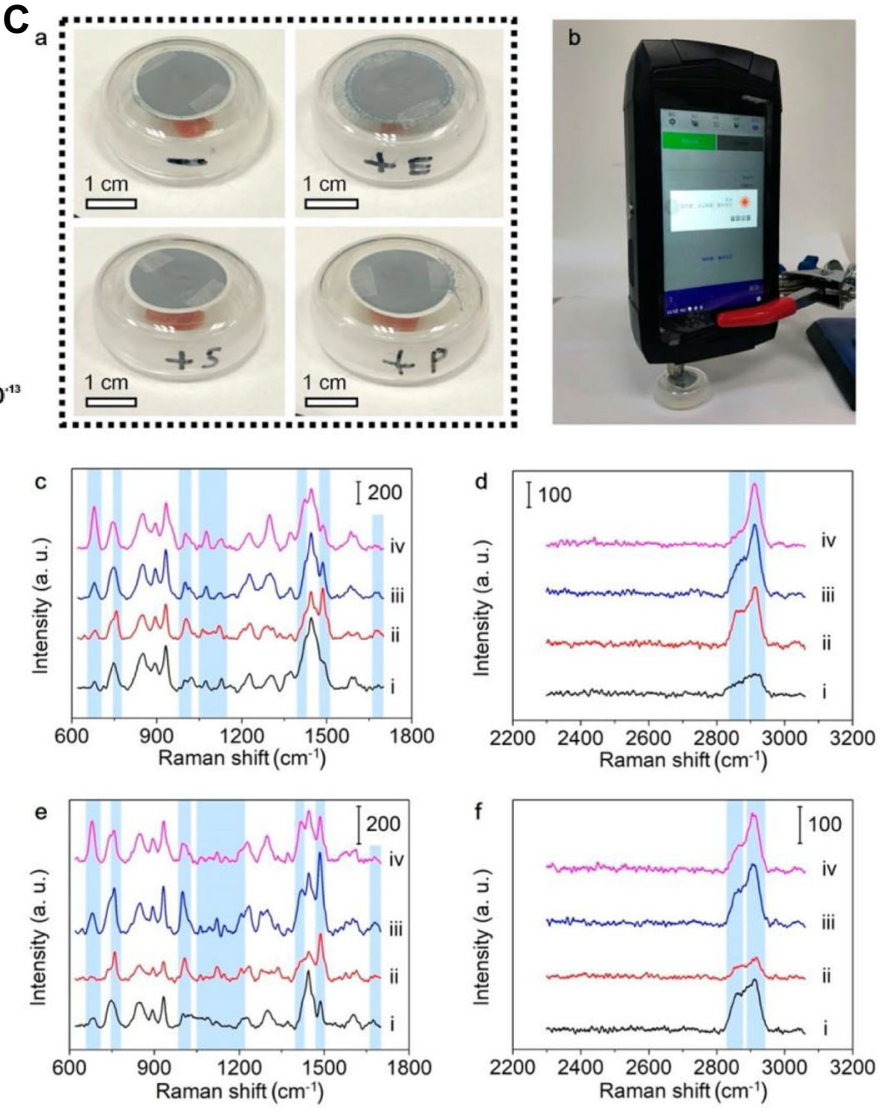

Photo showing the point-of-care sensing with a user-friendly SERS device. c-f Typical SERS spectra of (i), E. coli (ii), S. aureus (iii), and $P$. aeruginosa (iv) acquired from $(\mathrm{c}, \mathrm{d})$ medium and $(\mathrm{e}, \mathrm{f})$ inoculated pork samples. Reprinted with permission from ref. 82
Staphylococcus aureus, 2 isolates; Stenotrophomonas maltophilia, 2 isolates; Vibrio vulnificus, 1 isolate) were simultaneously identified, demonstrating the potential for multiplex bacterial detection. The successful detection of bacterial DNA discussed above was realized based on using artificially synthesized DNA or PCR products [100]. Unfortunately, nearly few of the aforementioned studies realized the detection of bacteria in real samples without the use of PCR, which inevitably increases the time required for PCR reaction to the total detection time.
A .
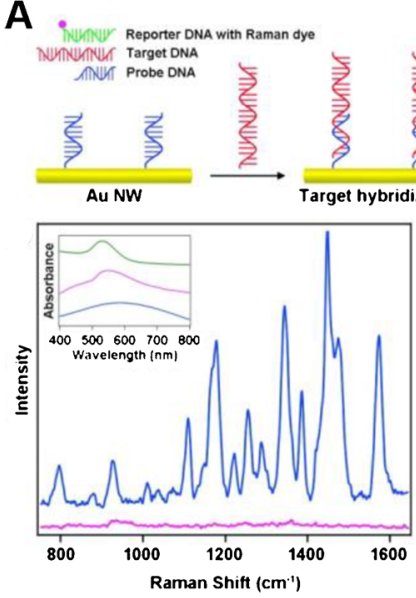

B
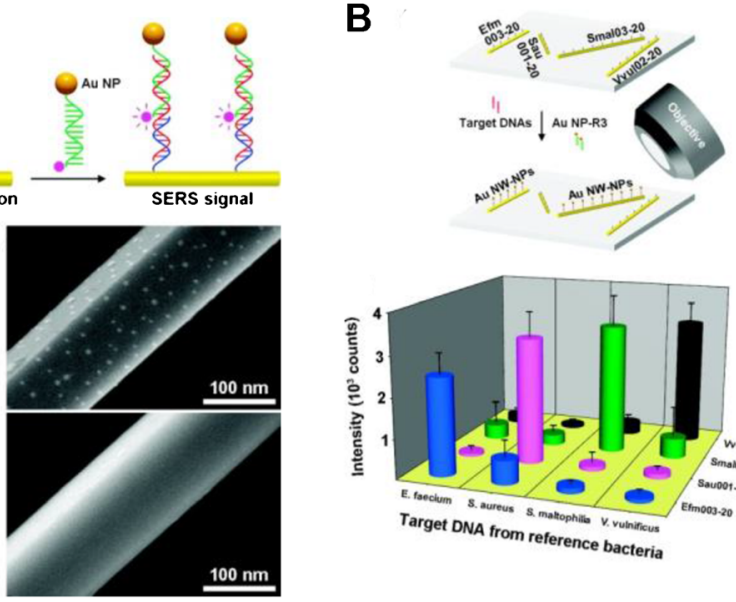
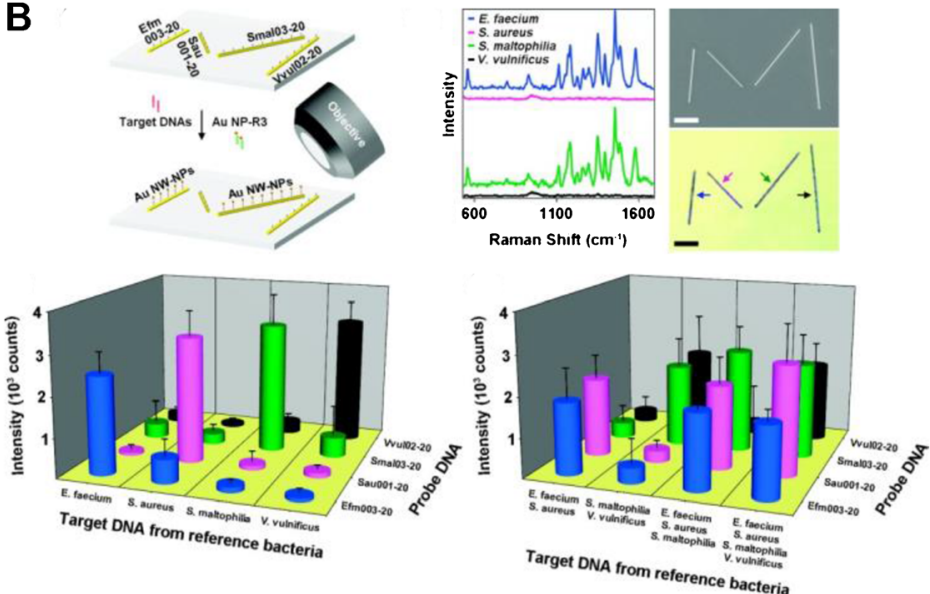

Fig. 3 a Scheme of the DNA detection with the Au particle-on-wire SERS platform. b Representation of the SERS detection of patterned multiplex pathogen DNA. Reprinted with permission from ref. 99 


\section{Labeled detection of bacteria}

The differentiation of bacteria based on their SERS signals poses many challenges, especially for a mixture of different bacteria. Hence, a secondary confirmation is often required, which mainly base on assessing the immunological properties of target bacteria by using immune molecules such as antibodies and aptamers $[61,101,102]$. The core of the immuneSERS platform is the immune-conjugated nanoparticles, where the conjugated immune molecules are specific to the target bacteria and the nanoparticles serve as the SERS-active substrates. These immune molecules are often labeled with Raman reporter molecules, which are small molecules with strong and distinguishable Raman signals. The detection and differentiation of the bacteria can thus be achieved through the different labeled Raman reporter molecules.

Combining SERS with classical immunoassay method offers the possibility to selectively capture and detect target bacteria with high sensitively. A sandwich type SERS sensing platform was established by using 4-mercaptobenzoicacid (MBA)-coated Au nanoparticles conjugated with polyclonal antibodies and MNPs $\left(\mathrm{Fe}_{3} \mathrm{O}_{4}\right)$ modified with monoclonal antibodies. Escherichia coli $\mathrm{O} 157: \mathrm{H} 7(10 \mathrm{CFU} / \mathrm{mL})$ from both pure cultures and ground beef samples were detected within $1 \mathrm{~h}$ and $3 \mathrm{~h}$, respectively [57]. Dual antibodies including Escherichia coli and Staphylococcus aureus were used for the functionalization of Au nanoparticles with magnetic beads were employed to construct a simultaneous SERS detection system. The Au nanoparticles with SERS probes of triple bonds at 2105 and $2227 \mathrm{~cm}^{-1}$ could prevent the interferences from the coexisting constituents in the fingerprint area. This method showed the LODs for Escherichia coli and

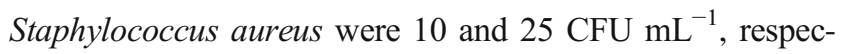
tively. Moreover, it enabled simultaneous detection of these two bacteria both in bottled water and milk samples, demonstrating the application to real samples [58].

.Antibodies were used in the abovementioned studies as sensitive and selective recognition agents. However, it has been shown that there are still limitations in the use of antibodies for recognition in biosensing and bioanalysis [103-105]. For example, antibody production is expensive and time-consuming, and the specific binding greatly depend on the environmental conditions, which may be detrimental to the analysis of environmental or food samples. Therefore, more and more attentions have been focused on the development of alternative recognition molecules. Aptamers are rapidly emerging with high specificity and environmental robustness $[61,106,107]$. They are single-stranded DNA or RNA sequences that can potentially recognized any targets selectively. Compared with antibodies, aptamers have the advantages of small size, readily amenable to chemical synthesis, cost-effective, high stability, reproducibility between batches, and unlimited target size or immune response [108-111]. In line with the potential advantages of aptamers being used as excellent capture biomolecules, they have been explored as one of the most promising candidates for manufacturing next-generation biosensors. Díaz-Amaya et al. described the effective sensing of Escherichia coli $\mathrm{O} 157: \mathrm{H} 7$ by using multi functionalized gold nanoparticles with specific aptamer and Raman reporter. This SERS-based method exhibited high sensitivity and specificity for Escherichia coli and could be used both for both pure culture and ground beef samples with LOD of $\sim 10 \mathrm{CFU} \mathrm{mL} \mathrm{C}^{-1}$ and $\sim 100 \mathrm{CFU} \mathrm{mL}^{-1}$, respectively [61]. A aptamers-based SERS screening method was developed to detect and filtrate Salmonella enterica serovar Enteritidis in water. A DNA aptamer was used for targeting Salmonella Enteritidis and labeling with specificity, which was attached to an adenine and fluorescein (FAM) chain to determine the presence or absence of Salmonella Enteritidis. Target bacterial cells were identified and further concentrated by combining with a vacuum filtration system. Through an extra filtration of $\mathrm{Au} \mathrm{NPs}$, the aptamer signals were obtained and employed for SERS mapping, indicating whether the existence of specific bacterial strains. The specificity of this approach was verified and the sensitivity was reported as $10^{3} \mathrm{CFU} / \mathrm{mL}$ within the detection time of $3 \mathrm{~h}$ [62]. Simultaneous quantification of Salmonella typhimurium and Staphylococcus aureus was also demonstrated by employing aptamers and nanostructures. A SERS-based platform was developed with the well-designed signal probe and capture probe, among which the former referred to gold nanoparticles (AuNPs) functionalized with both Raman reporter and aptamers, and the latter referred to aptamer-coated AuNPs. The detection limit for Staphylococcus aureus and Salmonella typhimurium were $35 \mathrm{CFU} \mathrm{mL} \mathrm{m}^{-1}$ and $15 \mathrm{CFU} \mathrm{mL}^{-1}$, respectively [65]. To further improve the sensitivity, a magnetically assisted biosensor consisting of both SERS substrate (magnetic NPs coated with Ag) and SERS tag (Au-DTNB@Ag-DTNB core-shell plasmonic NPs) was designed for detection of Staphylococcus aureus. The positions of double-layer DTNB and LSPR matched well with the laser excitation wavelength, which enabled 10 times of enhancement in the Raman signals compared with the commonly used SERS tag AuNR-DTNB. This nanostructure-based SERS method achieved the LOD of 10 cells $/ \mathrm{mL}$ for Staphylococcus aureus [63].

In further development work, various morphology-based SERS tags were developed for the simultaneous and sensitive detection of Escherichia coli O157:H7 and Salmonella typhimurium, which was based on co-functionalized $\mathrm{Au}$ NRs with aptamer and Raman reporter. The one-pot synthesized tags provided characteristic SERS signals with high stability, as well as specificity for biorecognition. In the Au NRmediated regeneration process, SERS tags with octahedral cracks and small protrusions were prepared and coated by specific aptamers and two kinds of Raman reporter. With the aid of antibody-conjugated bulk-modified MNPs, Salmonella 
typhimurium and Escherichia coli in the range of 10$10^{6} \mathrm{CFU} \mathrm{mL}^{-1}$ were detected simultaneously with LODs of 8 and $5 \mathrm{CFU} \mathrm{mL}{ }^{-1}$, respectively (Fig. 4a) [59]. Similarly, the same group also reported SERS detection of E. coli $\mathrm{O} 157: \mathrm{H} 7$ with a one-pot using self-prepared multifunctional $\mathrm{Au}$ nanobones, showing a LOD of $3 \mathrm{CFU} \mathrm{mL}^{-1}$ [60]. Moreover, a uniform approach for Staphylococcus aureus enterotoxin B (SEB) sensing was established by applying core-shell Fe-Au MNPs and Raman reporter-tagged Au nanorods as SERS probes. Magnetic Au nanorods modified with aptamers were used for targeting SEB. After SEB separation from matrix, the SERS signals were obtained with Au nanorods serving as SERS probes. It showed that SERS signals were linearly related with the concentration of SEB in the range $2.5 \mathrm{fM}$ to $3.2 \mathrm{nM}$, with a LOD for homogeneous analysis of $224 \mathrm{aM}$. This specificity and real application of this method was evaluated by SEB measurement in artificially contaminated milk, blood, and urine [112].

.However, the colloid-based methods usually face limitations in reproducibility due to the small changes both in the cluster size and shape caused by the colloidal solution [113, 114]. To solve this problem, several solid phase substrates have been proposed for the labeled detection of bacteria. It has been reported that bacterial cells could be identified by the aptamer and further concentrated on a membrane with an incorporated vacuum filtration system [115-117]. A polydimethylsiloxane (PDMS) film modified with $\mathrm{Au}$ nanoparticle has been used as an active substrate. Aptamer-functionalized AuNP film combined with specific Raman reporters (4-mercaptobenzoic acid/Nile-blue A) was further prepared as a pathogen-specific SERS probe. After successful capturing by Apt-Au-PDMS membrane, the pathogen was then combined to the SERS probe, forming a sandwich type analysis for multiple pathogens. Using Vibrio hemolyticus and Salmonella typhimurium as model targets, respective concentrations of 18 and $27 \mathrm{CFU} \mathrm{mL}{ }^{-1}$ were detected with high selectivity. This platform can be successfully applied for the detection of pathogenic bacteria in marine food samples, showing the recovery rate between $82.9 \%$ and $95.1 \%$ [66]. In addition, the aptamer-functionalized AuNP-PDMS enabled the detection of Staphylococcus aureus in fish samples with high sensitivity and selectively. It exhibited a linear detection range of $4.3 \times 10-4.3 \times 10^{7} \mathrm{CFU} \mathrm{mL}^{-1}$, with a detection limit of $13 \mathrm{CFU} \mathrm{mL}^{-1}$ (Fig. 4b) [64].

\section{Detection of food-borne viruses}

Food-borne viruses that include norovirus, hepatitis $\mathrm{A}$ and $\mathrm{E}$ viruses, swine fever virus, rotavirus, and coronavirus are mainly transmitted through the fecal-oral route as well as from the intake of contaminated water and food such as fruits, uncooked vegetables, and shellfish [118-120]. These viruses have low infectious doses and survive well in the host environments. Although many colonized individuals are asymptomatic or develop gastroenteritis within a few days, the excretion of the virus may last for several days or weeks [121-123]. Therefore, it is challenging to construct an effective disease surveillance system and expand the scope of virus surveillance through real-time virus identification. The SERS technique paves the way for a simplified, robust, and low-cost detection strategy for food-borne viruses. A summary of these typical SERSbased methods for the detection of food-borne virus is shown in Table 2.

\section{Label-free detection of viruses}

Viruses could be quickly and selectively distinguished with a direct SERS configuration in a confined nanostructured space. For example, Au substrates coupled with SERS were demonstrated for the detection of food- and water-borne viruses including norovirus, adenovirus, parvovirus, rotavirus, coronavirus, the Sendai virus, and herpes virus [124]. An Ag nanorod array substrate-based SERS method was devised to detect rotavirus quickly and sensitively. The SERS spectra of 8 rotaviruses were qualitatively detected for identification and classification of rotaviruses based on the $\mathrm{G}$ and $\mathrm{P}$ genotypes and strains. The accuracy was $>96 \%$ and the LOD was about $1 \times 10^{4} \mathrm{ffu} / \mathrm{mL}$ [126]. A similar direct method was reported to obtain the Raman spectra of respiratory syncytial virus (RSV) strains $\mathrm{A} /$ Long, $\mathrm{B}_{1}$, and $\mathrm{A}_{2}$ [128]. The collected SERS spectrum for each virus exhibited high repeatability. Based on the SERS spectra, 4 virus strains were classified by combining PCA and hierarchical cluster analysis. To help understand the origin of viruses and control disease outbreaks, it is usually necessary to isolate viruses from the infected sample for characterization. For this purpose, a portable microfluidic platform with carbon nanotube arrays featuring differential filtration porosity was constructed for rapid enrichment of the viruses and subsequent SERS identification. Rhinoviruses, influenza viruses, and parainfluenza viruses were successfully enriched such that a stoichiometric proportion of the viruses was maintained and when the samples contained multiple types of viruses, thus simulating co-infection. It took only a few minutes to capture and detect the viruses with an enrichment factor of 70 -fold. Highly sensitive detection could be achieved with $10^{2}$ $\mathrm{EID}_{50} / \mathrm{mL}(50 \%$ egg infective dose $/ \mu \mathrm{L})$ and the virus specificity of $90 \%$ [129]. This enrichment method combined with SERS identification constitutes an innovative system that can be used for rapid tracking and monitoring of virus outbreaks in real time. Therefore, the uniqueness of SERS provides molecular fingerprints for specific detection of viruses, laying the foundation for the direct application in biosensing. 

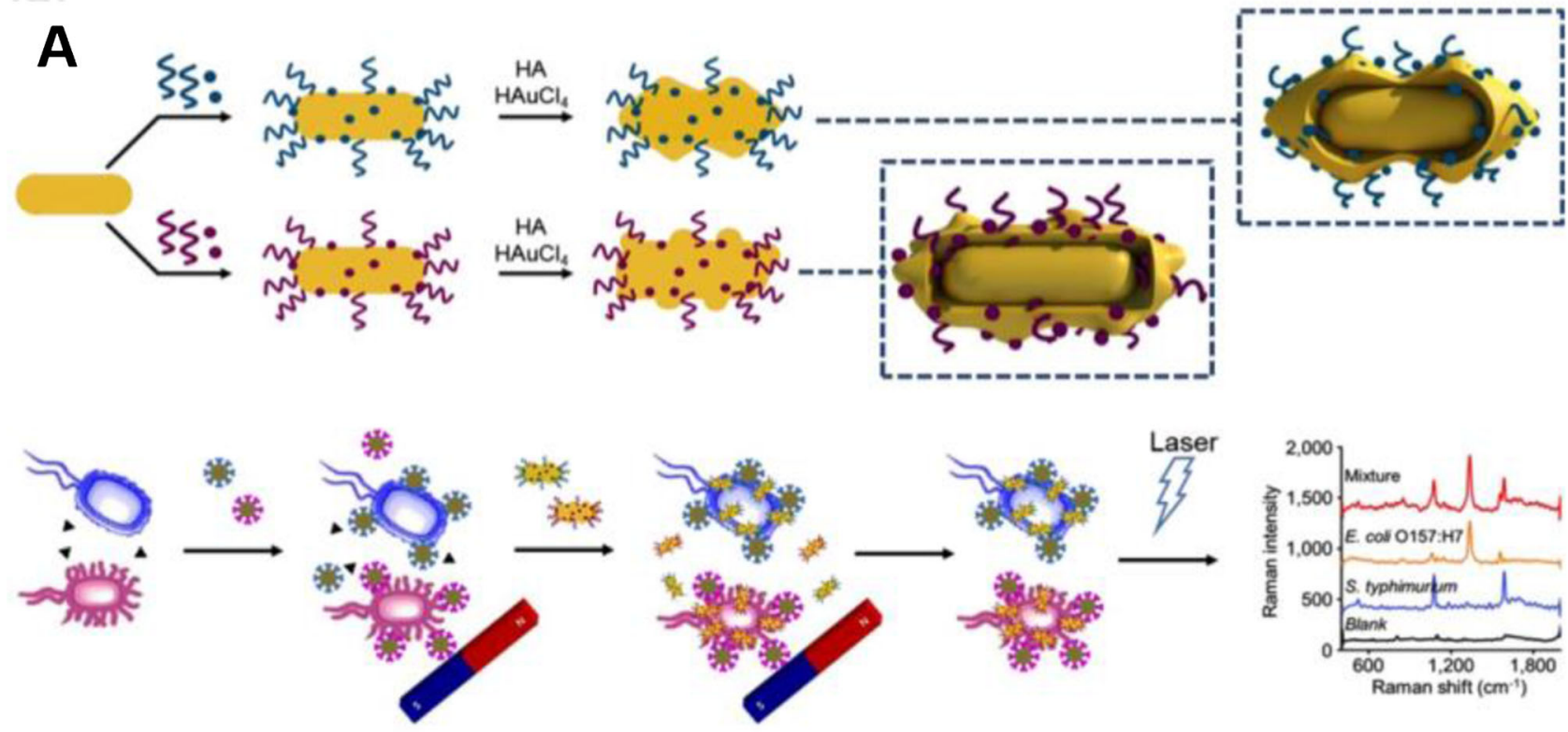

GNRs § Aptamer-1 - Reporter-1

$\Delta$ Matrix $\$$ Aptamer-2 - Reporter-2

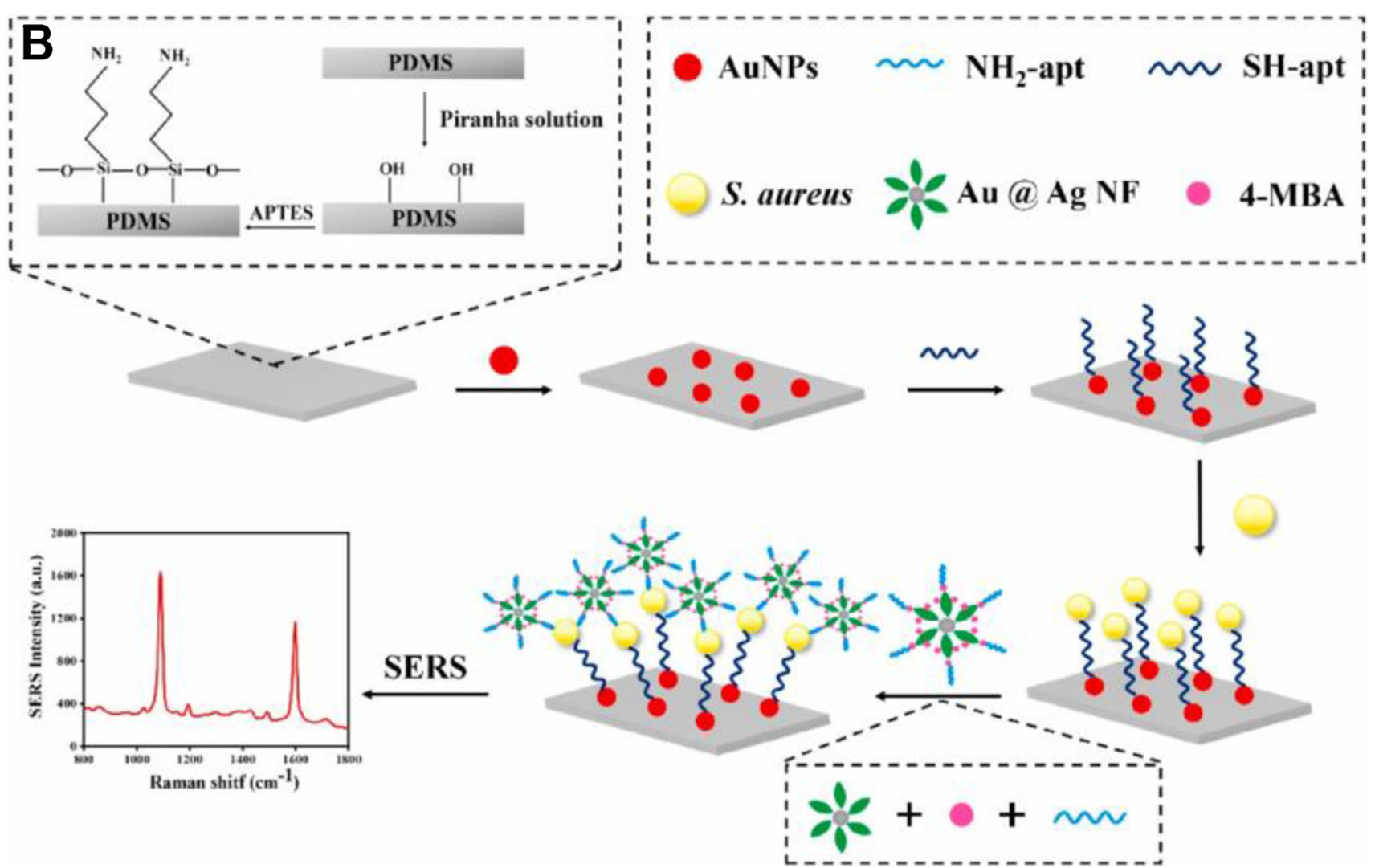

Fig. 4 a Schemes of various SERS tags and the application in bacteria detection. Reprinted with permission from ref. 59. b Schematic representation of the solid phase substrate for SERS detection. Reprinted with permission from ref. 64 
Table 2 Food-borne viruses detected by SERS

\begin{tabular}{|c|c|c|c|c|}
\hline Food-borne viruses & $\begin{array}{l}\text { Detection } \\
\text { strategy }\end{array}$ & Substrates & LOD & Ref. \\
\hline \multirow[t]{2}{*}{ norovirus } & Label-free & AuNPs & $10^{2} \mathrm{Pfu} \mathrm{m}{ }^{-1}$ & [124] \\
\hline & Labeled & $\begin{array}{l}\text { Molybdenum trioxide nanocubes aligned on a } \\
\text { graphene oxide substrate }\end{array}$ & $\begin{array}{l}5.2 \mathrm{fg} / \mathrm{mL} ; 60 \mathrm{RNA} \\
\text { copies/mL }\end{array}$ & [125] \\
\hline \multirow[t]{3}{*}{ rotavirus } & Label-free & Au NPs & $10^{2} \mathrm{Pfu} \mathrm{ml} \mathrm{m}^{-1}$ & [124] \\
\hline & Label-free & Silver nanorod array & $1 \times 10^{4}$ ffu $\mathrm{mL}^{-1}$ & [126] \\
\hline & & $3 \mathrm{D} \mathrm{Au} / \mathrm{Fe}_{3} \mathrm{O}_{4}$-graphene oxide architecture & - & [127] \\
\hline $\begin{array}{l}\text { respiratory syncytial virus (RSV) strains } \\
\text { A/Long, B1, and A2 }\end{array}$ & Label-free & Silver nanorod array & $\overline{10} 0^{3} \mathrm{Pfu} \mathrm{ml}^{-1}$ & {$[128]$} \\
\hline $\begin{array}{l}\text { rhinovirus, influenza virus, parainfluenza } \\
\text { viruses }\end{array}$ & Label-free & $\begin{array}{l}\text { Portable microfluidic platform containing carbon } \\
\text { nanotube arrays }\end{array}$ & $10^{2} \mathrm{EID}_{50} / \mathrm{mL}$ & [129] \\
\hline hepatitis B virus antigen & Labeled & Au-Ag-coated $\mathrm{GaN}$ and $\mathrm{Au}$ nanoflowers & $0.01 \mathrm{IU} / \mathrm{mL}$ & [130] \\
\hline Avian influenza virus & Labeled & AuNPs and $\mathrm{Fe}_{3} \mathrm{O}_{4} / \mathrm{Au}$ & $10^{2} \mathrm{TCID}_{50} / \mathrm{mL}$ & [131] \\
\hline H1N1 virus human adenovirus & Labeled & $\mathrm{Fe}_{3} \mathrm{O}_{4} / \mathrm{AgNPs}$ & 50 and $10 \mathrm{Pfu} / \mathrm{mL}$ & [132] \\
\hline
\end{tabular}

\section{Labeled detection of viruses}

SERS substrate with antibodies modification could be employed to improve the detection sensitivity for viruses by comparing the Raman responses before and after viruses capture. A plasmonic Au-Ag-coated GaN substrate with unique fuchsin-labeled immuno-Au nanoflowers was prepared for the detection of HBsAg antigen in the blood plasma at $0.01 \mathrm{IU} /$ $\mathrm{mL}$ [130]. Magnetic $\mathrm{Fe}_{3} \mathrm{O}_{4}$ nanoparticles anchored with $\mathrm{Au} /$ $\mathrm{Ag}$ nanostructures have drawn widespread attention due to their superior versatility and stability, especially for SERS measurement of complex samples. Combining the SERS capability of $\mathrm{Au} / \mathrm{Ag}$ NPs and the enrichment advantages of $\mathrm{Fe}_{3} \mathrm{O}_{4}$, these magnetic SERS substrates enabled not only great enhancement in the Raman signals but also quick separation process under magnetic field. A series of immunosensors have been constructed for sensing of various viruses based on the magnetic SERS substrates. An antibody-attached 3D plasmonic-magnetic architecture was employed for SERS detection and complete removal of rotavirus from water samples at a concentration of about $6 \times 10^{5} \mathrm{PFU} / \mathrm{mL}$ (Fig. 5a) [127]. A magnetic SERS immunosensor was constructed to detect intact but inactivated influenza virus $\mathrm{H}_{3} \mathrm{~N}_{2}$ via a sandwich type structure consisting of 4-mercaptobenzoic acid-labeled $\mathrm{Au}$ nanoparticles, target influenza viruses and $\mathrm{Fe}_{3} \mathrm{O}_{4} / \mathrm{Au}$ NPs. With a portable Raman spectrometer, $\mathrm{H}_{3} \mathrm{~N}_{2}$ down to $10^{2}$ $\mathrm{TCID}_{50} / \mathrm{mL}$ could be detected and showed a linear detection range of $10^{2}$ to $5 \times 10^{3} \mathrm{TCID}_{50} / \mathrm{mL}$ [131]. These methods which exploit magnetic nanocomposites in SERS detection of viruses are limited in the ability to act as a magnetic separation tool with the SERS substrates. To expand the biochemical application, a SERS-based lateral flow immunoassay strip was designed for the detection of influenza $\mathrm{A} \mathrm{H}_{1} \mathrm{~N}_{1}$ virus and human adenovirus (HAdV) simultaneously. $\mathrm{Fe}_{3} \mathrm{O}_{4} @ \mathrm{Ag}$ NPs was prepared and employed as SERS nanotags, which were dual modified with Raman reporters and specific antibodies (Fig. 5b). It exhibits the several advanced functional features: identification of specific virus and accumulation on the magnetic NPs surface, direct SERS analysis of these virus on the lateral strip. $\mathrm{H}_{1} \mathrm{~N}_{1}$ and $\mathrm{HAdV}$ with concentrations of 50 and $10 \mathrm{PFU} / \mathrm{mL}$ could be detected, showing three orders of magnitude higher sensitivity compared with the standard gold strip method [132].

.SERS nanotags may suffer from unstable signals due to the aggregation or desorption of Raman reporters from the nanostructure surface [133, 134], that would weaken the analytical performance of the SERS method, including sensitivity, reproducibility, and overall reliability. To address these problems in norovirus detection, a dual SERS immunoassay was developed based on plasmonic/magnetic molybdenum trioxide nanocubes anchored on single-layer graphene oxide (Fig. 5c, d). Detailly, the immune magnetic nanoparticles and graphene oxide were employed as 2D SERS substrate/capture platform with molybdenum trioxide nanocubes using as SERS tag. They served as the signal reporter and were able to accommodate an additional Raman molecule as a co-reporter. Attributing to the applied magnetic-based separation process, norovirus was concentrated and identified in clinical samples with the favorable detection range of $10^{2}$ to $10^{6}$ RNA copies/mL [125].

.In conclusion of the presenting label-free and labeled methods, label-free methods own the advantages of simplicity and convenience and enable the collection of SERS spectra directly, but have difficulties in real sample analysis. Generally, pretreatment of samples or separation techniques are included to perform the SERS analysis, with further chemometrics employed for better understanding the results, while the labeled methods generally employ Raman reporter 


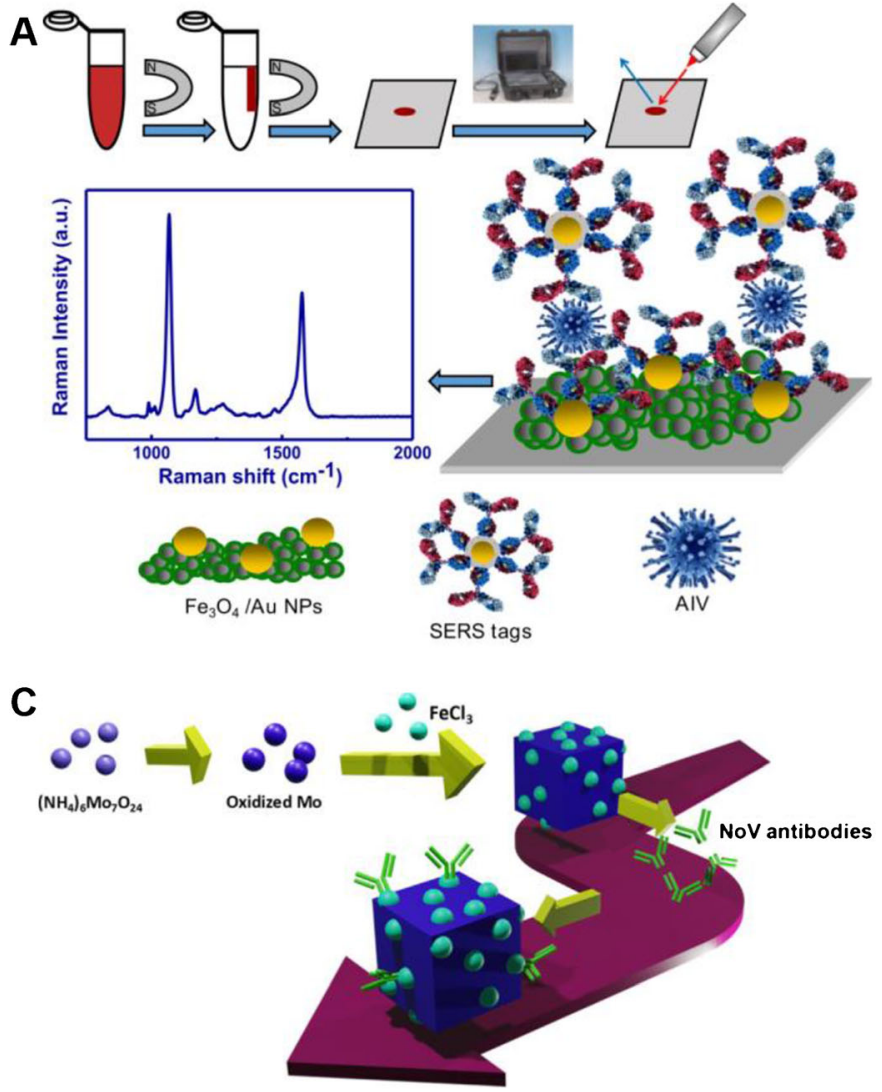

Fig. 5 a Schematic for the magnetic-based SERS immunoassay. Reprinted with permission from ref. 131. b The synthesis of antibodycoated $\mathrm{Fe}_{3} \mathrm{O}_{4} @ \mathrm{Ag}$ magnetic tags and the related strip detection of two respiratory viruses. Reprinted with permission from ref. 132. c, d A dual

molecules for SERS sensing. Taking advantage of the recognition agents such as antibodies or aptamers, these methods show a great increase in the specificity, which are more adaptable for real sample analysis.

\section{Conclusions and perspectives}

In this review, the advances on the SERS detection of pathogens over the past decades have been reviewed, focusing on the improvements in sensitivity, reproducibility, specificity, and the performance of in complex analytical scenarios. The progress in research demonstrates that SERS-based methods enable rapid detection of food-borne bacteria and viruses with high sensitivity as well as high specificity. Pathogen species can be successfully differentiated either through chemometric analysis or via secondary confirmation. Although these exciting research studies have resulted in dramatic advances in the field, the application of SERS in pathogens analysis still faces a number of challenges: (1) Most studies have not focused on real samples, hence there are clear differences in SERS detection capabilities between standard culture medium and real samples. The real sample components will interfere with the

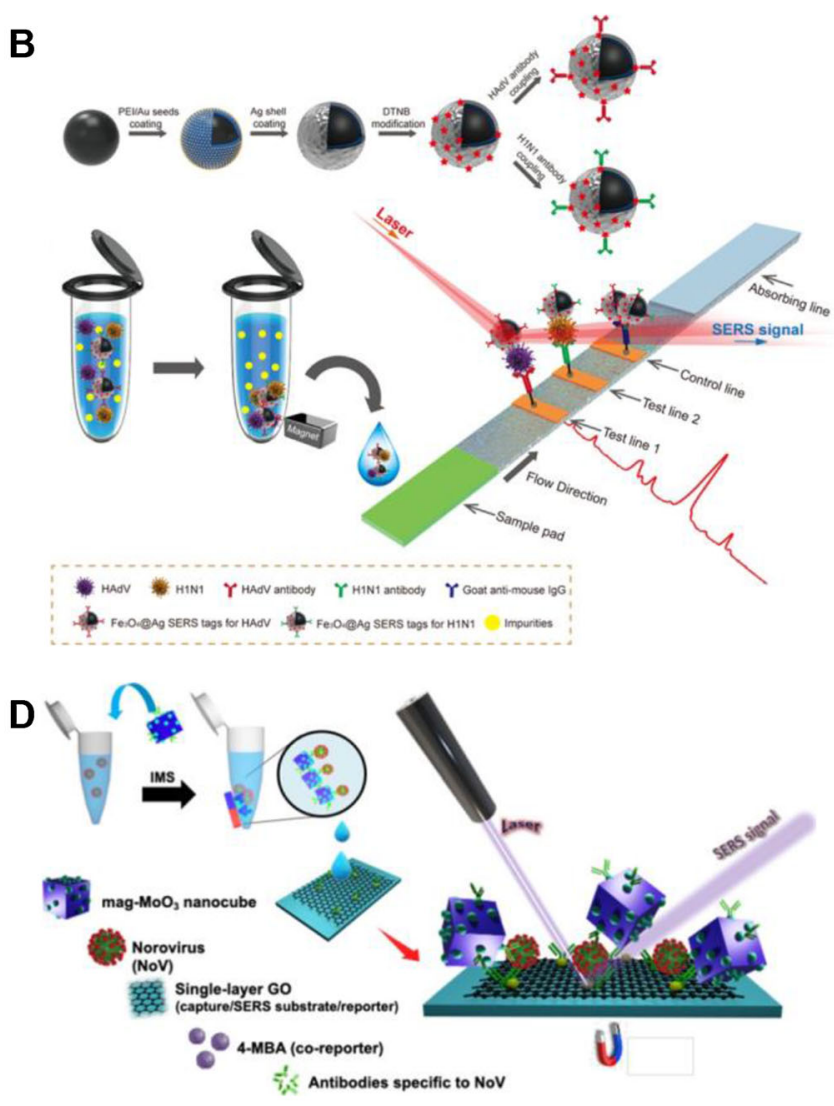

SERS immunoassay based on plasmonic/magnetic molybdenum trioxide nanocubes anchored on single-layer graphene oxide. Reprinted with permission from ref. 125

SERS response and result in certain difficulties to practical applications. (2) The SERS performance of different methods is quite different, mainly reflecting differences in the design and structure of the nano-enhanced substrates. Therefore, more in-depth research is needed to further optimize the conditions to improve practical application of SERS. (3) The relatively high cost of SERS-active substrates and the complications associated with complex samples may be the biggest hurdle towards development of widely recognized and robust SERS platforms for large batch sample analysis. Thus, deepen understanding of the relationship between nanostructure substrate and the SERS enhancement is significant for construction and design biological sensors with high sensitivity and reproducibility [135]. In recent years, combination of SERS with other analytical methods offers a potential solution for these challenges [136]. An electrochemical SERS (EC-SERS) platform was proposed to improve the sensitivity and selectivity, as well as stimulate more biological relevant electric field environment [137]. It has been proposed for the detection and identification of food-borne pathogens by using carbon screen printed electrodes with nanoparticles coating on the working electrode [138]. Gram-positive B. megaterium and Gram-negative $E$. coli $K-12$ were detected and differentiated 
with improved SERS peak intensities and spectral richness, showing a promise for bacterial screening. Further coupled the EC-SERS method with filter system, control studies were performed to ascertain the EC-SERS signals for bacterial sample [139]. It was reported that the SERS spectra collected for bacterial cultures were due to the released small molecules metabolites in response to environmental stressors. Other analytical methods, such as separation and microfluidic techniques have also been reported for bacteria concentration, which would further improve the sensing ability [136]. In time, we are confident these problems can be solved through fast developments in nanotechnology and integration with biology. Thus, we anticipate more research efforts will be devoted to applying SERS in clinical diagnostics and safety evaluation, where dynamic and ultra-fast detection is a crucial requirement.

Supplementary Information The online version contains supplementary material available at https://doi.org/10.1007/s00604-021-04864-4.

Acknowledgments This work was financially supported by the National Natural Science Foundations of China (Nos. 21974055, 21906054) and the Fund of Xuzhou Science and Technology Key R\&D Program (Social Development) Project (No. KC20178).

\section{Declarations}

Conflict of interest The authors declare that they have no conflict of interest.

Conflict of interest The authors declare that they have no competing of interests.

\section{References}

1. Arabi YM, Murthy S, Webb S (2020) COVID-19: a novel coronavirus and a novel challenge for critical care. Intensive Care Med 46:833-836

2. Wang D, Hu B, Hu C, Zhu F, Liu X, Zhang J, Wang B, Xiang H, Cheng Z, Xiong Y, Zhao Y, Li Y, Wang X, Peng Z Clinical characteristics of 138 hospitalized patients with 2019 novel coronavirus-infected pneumonia in wuhan, China. JAMA 2020(323):1061-1069

3. Fisher D, Reilly A, Zheng AKE, Cook AR, Anderson D (2020) Seeding of outbreaks of COVID-19 by contaminated fresh and frozen food. BioRxiv. https://doi.org/10.1101/2020.08.17.255166

4. Bhalla N, Pan Y, Yang Z, Payam AF (2020) Opportunities and challenges for biosensors and nanoscale analytical tools for pandemics: COVID-19. ACS Nano 14:7783-7807

5. Duda-Chodak A, Lukasiewicz M, Zięć G, Florkiewicz A, Filipiak-Florkiewicz A (2020) Covid-19 pandemic and food: present knowledge, risks, consumers fears and safety. Trends Food Sci Technol 105:145-160

6. In't Veld JHH (1996) Microbial and biochemical spoilage of foods: an overview. Int J Food Microbiol 33:1-18

7. Gram L, Ravn L, Rasch M, Bruhn JB, Christensen AB, Givskov M (2002) Food spoilage-interactions between food spoilage bacteria. Int J Food Microbiol 78:79-97
8. Zhang YJ, Li S, Gan RY, Zhou T, Xu DP, Li HB (2015) Impacts of gut bacteria on human health and diseases. Int J Mol Sci 16: 7493-7519

9. Sansonetti P, Rupture J (2001) Invasion and inflammatory destruction of the intestinal barrier by Shigella, making sense of prokaryote-eukaryote cross-talks. FEMS Microbiol Rev 25:3-14

10. Yeni F, Acar S, Polat ÖG, Soyer YEȘIM, Alpas HAMİ (2014) Rapid and standardized methods for detection of foodborne pathogens and mycotoxins on fresh produce. Food Control 40:359-367

11. McKILLIP JL, Drake M (2004) Real-time nucleic acid-based detection methods for pathogenic bacteria in food. J Food Protect 67: 823-832

12. Chen Y, Qian C, Liu C, Shen H, Wang Z, Ping J, Wu J, Chen H (2020) Nucleic acid amplification free biosensors for pathogen detection. Biosens Bioelectron 153:112049

13. Kim JH, Oh SW (2020) Pretreatment methods for nucleic acidbased rapid detection of pathogens in food: a review. Food Control 121:107575

14. Hill WE, Wachsmuth K (1996) The polymerase chain reaction: applications for the detection of foodborne pathogens. Crit Rev Food Sci Nutr 36:123-173

15. Yoo SM, Lee SY (2016) Optical biosensors for the detection of pathogenic microorganisms. Trends Biotechnol 34:7-25

16. Da-Silva E, Baudart J, Barthelmebs L (2018) Biosensing platforms for Vibrio bacteria detection based on whole cell and nucleic acid analysis: a review. Talanta 190:410-422

17. Zarei M (2017) Portable biosensing devices for point-of-care diagnostics: recent developments and applications. Trac-Trend Anal. Chem. 91:26-41

18. Xu K, Zhou R, Takei K, Hong M (2019) Toward flexible surfaceenhanced Raman scattering (SERS) sensors for point-of-care diagnostics. Adv Sci 6:1900925

19. Li DW, Qu LL, Hu K, Long YT, Tian H (2015) Monitoring of endogenous hydrogen sulfide in living cells using surface-enhanced Raman scattering. Angew Chem Int Ed 127:12949-12952

20. Lane LA, Qian X, Nie S (2015) SERS nanoparticles in medicine: from label-free detection to spectroscopic tagging. Chem Rev 115: 10489-10529

21. Zheng T, Zhou Y, Feng E, Tian Y (2020) Surface-enhanced Raman scattering on 2D nanomaterials: recent developments and applications. Chin J Chem 39:745-756. https://doi.org/10.1002/ cjoc. 202000453

22. Ding SY, Yi J, Li JF, Ren B, Wu DY, Panneerselvam R, Tian ZQ (2016) Nanostructure-based plasmon-enhanced Raman spectroscopy for surface analysis of materials. Nat Rev Mater 1:1-16

23. Cardinal MF, Vander Ende E, Hackler RA, McAnally MO, Stair PC, Schatz GC, Van Duyne RP (2017) Expanding applications of SERS through versatile nanomaterials engineering. Chem Soc Rev 46:3886-3903

24. Luo SC, Sivashanmugan K, Liao JD, Yao CK, Peng HC (2014) Nanofabricated SERS-active substrates for single-molecule to virus detection in vitro: a review. Biosens Bioelectron 61:232-240

25. Qu LL, Li DW, Xue JQ, Zhai WL, Fossey JS, Long YT (2012) Batch fabrication of disposable screen printed SERS arrays. Lab Chip 12:876-881

26. Kneipp J, Kneipp H, Kneipp K (2008) SERS-a single-molecule and nanoscale tool for bioanalytics. Chem Soc Rev 37:1052-1060

27. Jing C, Gu Z, Xie T, Long YT (2016) Color-coded imaging of ElectroChromic process at single nanoparticle level. Chem Sci 7: 5347-5351

28. Chen HY, Lin MH, Wang CY, Chang YM, Gwo S (2015) Largescale hot spot engineering for quantitative SERS at the singlemolecule scale. J Am Chem Soc 137:13698-13705

29. Zhai WL, Li DW, Qu LL, Fossey JS, Long YT (2012) Multiple depositions of ag nanoparticles on chemically modified agarose films for surface-enhanced Raman spectroscopy. Nanoscale 4:137-142 
30. Lim DK, Jeon KS, Kim HM, Nam JM, Suh YD (2010) Nanogapengineerable Raman-active nanodumbbells for single-molecule detection. Nat Mater 9:60-67

31. Yang S, Dai X, Stogin BB, Wong TS (2016) Ultrasensitive surface-enhanced Raman scattering detection in common fluids. Proc Natl Acad Sci 113:268-273

32. Efrima S, Bronk BV (1998) Silver colloids impregnating or coating bacteria. J Phys Chem B 102:5947-5950

33. Kearns H, Goodacre R, Jamieson LE, Graham D, Faulds K (2017) SERS detection of multiple antimicrobial-resistant pathogens using nanosensors. Anal Chem 89:12666-12673

34. Jarvis RM, Goodacre R (2008) Characterisation and identification of bacteria using SERS. Chem Soc Rev 37:931-936

35. Zhou H, Yang D, Ivleva NP, Mircescu NE, Niessner R, Haisch C (2014) SERS detection of bacteria in water by in situ coating with ag nanoparticles. Anal Chem 86:1525-1533

36. Gao W, Li B, Yao R, Li Z, Wang X, Dong X, Qu H, Li QX, Li N, Zhou B (2017) Intuitive label-free SERS detection of bacteria using aptamer-based in situ silver nanoparticles synthesis. Anal Chem 89:9836-9842

37. Cowcher DP, Xu Y, Goodacre R (2013) Portable, quantitative detection of Bacillus bacterial spores using surface-enhanced Raman scattering. Anal Chem 85:3297-3302

38. Yan F, Vo-Dinh T (2007) Surface-enhanced Raman scattering detection of chemical and biological agents using a portable Raman integrated tunable sensor. Sens Actuators B Chem 121:61-66

39. Pilot R (2018) SERS detection of food contaminants by means of portable Raman instruments. J Raman Spectrosc 49:954-981

40. Liu Y, Zhou H, Hu Z, Yu G, Yang D, Zhao J (2017) Label and label-free based surface-enhanced Raman scattering for pathogen bacteria detection: a review. Biosens Bioelectron 94:131-140

41. Zhang P, Setlow P, Li Y (2009) Characterization of single heatactivated Bacillus spores using laser tweezers Raman spectroscopy. Opt Express 17:16480-16491

42. Xie W, Qiu P, Mao C (2011) Bio-imaging, detection and analysis by using nanostructures as SERS substrates. J Mater Chem 21: 5190-5202

43. Zhang L, Li Y, Li DW, Jing C, Chen X, Lv M, Huang Q, Long YT, Willner I (2011) Single gold nanoparticles as real-time optical probes for the detection of NADH-dependent intracellular metabolic enzymatic pathways. Angew Chem Int Ed 123:6921-6924

44. Campion A, Kambhampati P (1998) Surface-enhanced Raman scattering. Chem Soc Rev 27:241-250

45. Alvarez-Puebla RA, Liz-Marzán LM (2012) SERS detection of small inorganic molecules and ions. Angew Chem Int Ed 51: 11214-11223

46. Bell SE, Sirimuthu NM (2008) Quantitative surface-enhanced Raman spectroscopy. Chem Soc Rev 37:1012-1024

47. Ye X, Demidov A, Rosca F, Wang W, Kumar A, Ionascu D, Zhu L, Barrick D, Wharton D, Champion PM (2003) Investigations of heme protein absorption line shapes, vibrational relaxation, and resonance Raman scattering on ultrafast time scales. J Phys Chem A 107:8156-8165

48. Yang M, Huang D, Hao P, Zhang F, Hou X, Wang X (1994) Study of the Raman peak shift and the linewidth of lightemitting porous silicon. J Appl Phys 75:651-653

49. Han M, Gao X, Su JZ, Nie S (2001) Quantum-dot-tagged microbeads for multiplexed optical coding of biomolecules. Nat Biotechnol 19:631-635

50. Smith WE (2008) Practical understanding and use of surface enhanced Raman scattering/surface enhanced resonance Raman scattering in chemical and biological analysis. Chem Soc Rev 37:955-964

51. Fan C, Hu Z, Mustapha A, Lin M (2011) Rapid detection of foodand waterborne bacteria using surface-enhanced Raman spectroscopy coupled with silver nanosubstrates. Appl Microbiol Biotechnol 92:1053-1061
52. Yuan K, Zheng J, Yang D, Jurado Sánchez BL, Liu X, Guo X, Liu C, Dina NE, Jian J, Bao Z, Hu Z (2018) Self-assembly of Au@ Ag nanoparticles on mussel shell to form large-scale 3D supercrystals as natural SERS substrates for the detection of pathogenic bacteria. ACS Omega 3:2855-2864

53. Li Y, Guo Y, Ye B, Zhuang Z, Lan P, Zhang Y, Zhong H, Liu H, Guo Z, Liu Z (2020) Rapid label-free SERS detection of foodborne pathogenic bacteria based on hafnium ditelluride-au nanocomposites. J Innov Opt Heal Sci 13:2041004

54. Huang D, Zhuang Z, Wang Z, Li S, Zhong H, Liu Z, Guo Z, Zhang W (2019) Black phosphorus-au filter paper-based threedimensional SERS substrate for rapid detection of foodborne bacteria. Appl Surf Sci 497:143825

55. Wu X, Xu C, Tripp RA, Huang YW, Zhao Y (2013) Detection and differentiation of foodborne pathogenic bacteria in mung bean sprouts using field deployable label-free SERS devices. Analyst. 138:3005-3012

56. Wang W, Hynninen V, Qiu L, Zhang A, Lemma T, Zhang N, Ge H, Toppari JJ, Hytönen VP, Wang J (2017) Synergistic enhancement via plasmonic nanoplate-bacteria-nanorod supercrystals for highly efficient SERS sensing of food-borne bacteria. Sens. Actuators B Chem. 239:515-525

57. Cho IH, Bhandari P, Patel P, Irudayaraj J (2015) Membrane filterassisted surface enhanced raman spectroscopy for the rapid detection of E. coli O157: H7 in Ground Beef. Biosens Bioelectron 64:171-176

58. Bai X, Shen A, Hu J (2020) A sensitive SERS-based sandwich immunoassay platform for simultaneous multiple detection of foodborne pathogens without interference. Anal Methods 12(40):4885-4891

59. Li Y, Lu C, Zhou S, Fauconnier ML, Gao F, Fan B, Lin J, Wang F, Zheng J (2020) Sensitive and simultaneous detection of different pathogens by surface enhanced Raman scattering based on aptamer and Raman reporter comediated gold tags. Sens. Actuators B Chem. 317:128182

60. Zhou S, Lu C, Li Y, Xue L, Zhao C, Tian G, Bao Y, Tang L, Lin J, Zheng J (2020) Gold nanobones enhanced ultrasensitive surfaceenhanced Raman scattering aptasensor for detecting Escherichia coli O157:H7. ACS Sens 5:588-596

61. Díaz-Amaya S, Lin LK, Deering AJ, Stanciu LA (2019) Aptamerbased SERS biosensor for whole cell analytical detection of $E$. coli O157: H7. Anal Chim Acta 1081:146-156

62. Gao S, He L (2019) Development of a filtration-based SERS mapping platform for specific screening of Salmonella enterica serovar Enteritidis. Anal Bioanal Chem 411:7899-7906

63. Wang J, Wu X, Wang C, Shao N, Dong P, Xiao R, Wang S (2015) Magnetically assisted surface-enhanced Raman spectroscopy for the detection of Staphylococcus aureus based on aptamer recognition. ACS Appl Mater Interfaces 7:20919-20929

64. Zhu A, Ali S, Xu Y, Ouyang Q, Chen Q (2020) A SERS aptasensor based on AuNPs functionalized PDMS film for selective and sensitive detection of Staphylococcus aureus. Biosens Bioelectron 172:112806

65. Zhang H, Ma X, Liu Y, Duan N, Wu S, Wang Z, Xu B (2015) Gold nanoparticles enhanced SERS aptasensor for the simultaneous detection of Salmonella typhimurium and Staphylococcus aureus. Biosens Bioelectron 74:872-877

66. Duan N, Shen M, Qi S, Wang W, Wu S, Wang Z (2020) A SERS aptasensor for simultaneous multiple pathogens detection using gold decorated PDMS substrate. Spectrochim Acta A 230:118103

67. Zhang X, Young MA, Lyandres O, Van Duyne RP (2005) Rapid detection of an anthrax biomarker by surface-enhanced Raman spectroscopy. J Am Chem Soc 127:4484-4489

68. Cummins CS, Harris H (1956) The chemical composition of the cell wall in some Gram-positive bacteria and its possible value as a taxonomic character. Microbiology. 14:583-600 
69. Gracie K, Correa E, Mabbott S, Dougan JA, Graham D, Goodacre R, Faulds K (2014) Simultaneous detection and quantification of three bacterial meningitis pathogens by SERS. Chem Sci 5:10301040

70. Madiyar FR, Bhana S, Swisher LZ, Culbertson CT, Huang X, Li J (2015) Integration of a nanostructured dielectrophoretic device and a surface-enhanced Raman probe for highly sensitive rapid bacteria detection. Nanoscale 7:3726-3736

71. Xu J, Zhang L, Gong H, Homola JÍ, Yu Q (2011) Tailoring plasmonic nanostructures for optimal SERS sensing of small molecules and large microorganisms. Small. 7:371-376

72. Stiles PL, Dieringer JA, Shah NC, Van Duyne RP (2008) Surfaceenhanced Raman spectroscopy. Annu Rev Anal Chem 1(1):601626

73. Su G, Yang S, Jiang Y, Li J, Li S, Ren JC, Liu W (2019) Modeling chemical reactions on surfaces: the roles of chemical bonding and Van Der Waals interactions. Prog Surf Sci 94:100561

74. Liu S, Li H, Hassan MM, Zhu J, Wang A, Ouyang Q, Zareef M, Chen Q (2019) Amplification of Raman spectra by gold nanorods combined with chemometrics for rapid classification of four Pseudomonas. Int J Food Microbiol 304:58-67

75. Liu TY, Tsai KT, Wang HH, Chen Y, Chen YH, Chao YC, Chang HH, Lin CH, Wang JK, Wang YL (2011) Functionalized arrays of Raman-enhancing nanoparticles for capture and culture-free analysis of bacteria in human blood. Nat Commun 2:538

76. Zhang L, Xu J, Mi L, Gong H, Jiang S, Yu Q (2012) Multifunctional magnetic-plasmonic nanoparticles for fast concentration and sensitive detection of bacteria using SERS. Biosens Bioelectron 31:130-136

77. Villa JE, Quiñones NR, Fantinatti-Garboggini F, Poppi RJ (2019) Fast discrimination of bacteria using a filter paper-based SERS platform and PLS-DA with uncertainty estimation. Anal Bioanal Chem 411:705-713

78. Jarvis RM, Brooker A, Goodacre R (2006) Surface-enhanced Raman scattering for the rapid discrimination of bacteria. Faraday Discuss 132:281-292

79. Klein D, Breuch R, von der Mark S, Wickleder C, Kaul P (2019) Detection of spoilage associated bacteria using Ramanmicrospectroscopy combined with multivariate statistical analysis. Talanta. 196:325-328

80. Wu X, Chen J, Li X, Zhao Y, Zughaier SM (2014) Culture-free diagnostics of pseudomonas aeruginosa infection by silver nanorod array based SERS from clinical sputum samples. Nanomedicine. 10:1863-1870

81. Guo Y, Girmatsion M, Li HW, Xie Y, Yao W, Qian H, Abraha B, Mahmud A (2020) Rapid and ultrasensitive detection of food contaminants using surface-enhanced Raman spectroscopy-based methods. Crit Rev Food Sci Nutr:1-14

82. Guo J, Liu Y, Yang Y, Li Y, Wang R, Ju H (2020) A filter supported surface-enhanced Raman scattering "nose" for pointof-care monitoring of gaseous metabolites of bacteria. Anal Chem 92:5055-5063

83. Cheung M, Lee WW, Cowcher DP, Goodacre R, Bell SE (2016) SERS of meso-droplets supported on superhydrophobic wires allows exquisitely sensitive detection of dipicolinic acid, an anthrax biomarker, Considerably Below the Infective Dose. ChemComm 52:9925-9928

84. Meier H, Amann R, Ludwig W, Schleifer KH (1999) Specific oligonucleotide probes for in situ detection of a major group of Gram-positive bacteria with low DNA G+ C content. Syst Appl Microbiol 22:186-196

85. Templier V, Roux A, Roupioz Y, Livache T (2016) Ligands for label-free detection of whole bacteria on biosensors: a review. Trac-Trend Anal Chem 79:71-79

86. Nelson KE, Fouts DE, Mongodin EF, Ravel J, DeBoy RT, Kolonay JF, Rasko DA, Angiuoli SV, Gill SR, Paulsen IT,
Peterson J (2004) Whole genome comparisons of serotype 4b and $1 / 2$ a strains of the food-borne pathogen listeria monocytogenes reveal new insights into the core genome components of this species. Nucleic Acids Res 32:2386-2395

87. Tettelin H, Masignani V, Cieslewicz MJ, Eisen JA, Peterson S, Wessels MR, Paulsen IT, Nelson KE, Margarit I, Read TD, Madoff LC (2002) Complete genome sequence and comparative genomic analysis of an emerging human pathogen, serotype $\mathrm{V}$ streptococcus Agalactiae. Proc Natl Acad Sci 99:12391-12396

88. Parab HJ, Jung C, Lee JH, Park HG (2010) A gold nanorod-based optical DNA biosensor for the diagnosis of pathogens. Biosens Bioelectron 26:667-673

89. Hu ZL, Li MY, Liu SC, Ying YL, Long YT (2019) A lithium-ionactive aerolysin nanopore for effectively trapping long singlestranded DNA. Chem Sci 10:354-358

90. Liu G, Wan Y, Gau V, Zhang J, Wang L, Song S, Fan C (2008) An enzyme-based E-DNA sensor for sequence-specific detection of femtomolar DNA targets. J Am Chem Soc 130:6820-6825

91. Liu CH, Li ZP, Du BA, Duan XR, Wang YC (2006) Silver nanoparticle-based ultrasensitive chemiluminescent detection of DNA hybridization and single-nucleotide polymorphisms. Anal Chem 78:3738-3744

92. Aparicio S, Chapman J, Stupka E, Putnam N, Chia JM, Dehal P, Christoffels A, Rash S, Hoon S, Smit A, Gelpke MDS (2002) Whole-genome shotgun assembly and analysis of the genome of Fugu Rubripes. Science. 297:1301-1310

93. Tang F, Barbacioru C, Wang Y, Nordman E, Lee C, Xu N, Wang X, Bodeau J, Tuch BB, Siddiqui A, Lao K (2009) mRNA-Seq whole-transcriptome analysis of a single cell. Nat Methods 6:377382

94. Hahn LW, Ritchie MD, Moore JH (2003) Multifactor dimensionality reduction software for detecting gene-gene and geneenvironment interactions. Bioinformatics 19:376-382

95. Guck J, Schinkinger S, Lincoln B, Wottawah F, Ebert S, Romeyke M, Lenz D, Erickson HM, Ananthakrishnan R, Mitchell D, Käs J (2005) Optical deformability as an inherent cell marker for testing malignant transformation and metastatic competence. Biophys J 88:3689-3698

96. Vo-Dinh T, Houck K, Stokes DL (1994) Surface-enhanced Raman gene probes. Anal Chem 66:3379-3383

97. Strelau KK, Brinker A, Schnee C, Weber K, Möller R, Popp J (2011) Detection of PCR products amplified from DNA of epizootic pathogens using magnetic nanoparticles and SERS. J Raman Spectrosc 42:243-250

98. van Lierop D, Faulds K, Graham D (2011) Separation free DNA detection using surface enhanced Raman scattering. Anal Chem 83:5817-5821

99. Kang T, Yoo SM, Yoon I, Lee SY, Kim B (2010) Patterned multiplex pathogen DNA detection by au particle-on-wire SERS sensor. Nano Lett 10(4):1189-1193

100. van Lierop D, Larmour IA, Faulds K, Graham D (2013) SERS primers and their mode of action for pathogen DNA detection. Anal Chem 85(3):1408-1414

101. Jayasena SD (1999) Aptamers: An emerging class of molecules that rival antibodies in diagnostics. Clin Chem

102. Zhou J, Rossi J (2017) Aptamers as targeted therapeutics: current potential and challenges. Nat Rev Drug Discov 16(3):181-202

103. Justino CI, Freitas AC, Pereira R, Duarte AC, Santos TAR (2015) Recent developments in recognition elements for chemical sensors and biosensors. TrAC Trend Anal Chem 68:2-17

104. McConnell EM, Holahan MR, DeRosa MC (2014) Aptamers as promising molecular recognition elements for diagnostics and therapeutics in the central nervous system. Nucleic Acid Ther 24:388-404

105. Fattahi Z, Khosroushahi AY, Hasanzadeh M (2020) Recent progress on developing of plasmon biosensing of tumor biomarkers: 
efficient method towards early stage recognition of cancer. Biomed Pharmacother 132:110850

106. Yildirim N, Long F, Gao C, He M, Shi HC, Gu AZ (2012) Aptamerbased optical biosensor for rapid and sensitive detection of $17 \beta$ estradiol in water samples. Environ Sci Technol 46:3288-3294

107. Wen G, Zhou L, Li T, Liang A, Jiang Z (2012) A sensitive surfaceenhanced Raman scattering method for determination of melamine with aptamer-modified nanosilver probe. Chin J Chem 30:869-874

108. Chen A, Yang S (2015) Replacing antibodies with aptamers in lateral flow immunoassay. Biosens Bioelectron 71:230-242

109. Dunn MR, Jimenez RM, Chaput JC (2017) Analysis of aptamer discovery and technology. Nat Rev Chem 1(10):1-16

110. Thiviyanathan V, Gorenstein DG (2012) Aptamers and the next generation of diagnostic reagents. Proteom Clin Appl 6(11-12): 563-573

111. Kong HY, Byun J (2013) Nucleic acid aptamers: new methods for selection, stabilization, and application in biomedical science. Biomol Ther 21:423-434

112. Temur E, Zengin A, Boyacı IH, Dudak FC, Torul H, Tamer U (2012) Attomole sensitivity of staphylococcal enterotoxin B detection using an aptamer-modified surface-enhanced Raman scattering probe. Anal Chem 84:10600-10606

113. Mayer M, Schnepf MJ, König TA, Fery A (2019) Colloidal selfassembly concepts for plasmonic metasurfaces. Adv Opt Mater 7: 1800564

114. Perumal J, Wang Y, Attia ABE, Dinish US, Olivo M (2021) Towards point-of-care SERS sensor for biomedical and Agrifood analysis applications: a review of recent advancements. Nanoscale 13:553-580. https://doi.org/10.1039/D0NR06832B

115. Yaseen T, Pu H, Sun DW (2018) Functionalization techniques for improving SERS substrates and their applications in food safety evaluation: a review of recent research trends. Trends Food Sci. Tech 72:162-174

116. Wang CH, Wu JJ, Lee GB (2019) Screening of highly-specific aptamers and their applications in paper-based microfluidic chips for rapid diagnosis of multiple bacteria. Sens. Actuators B Chem. 284:395-402

117. Walter A, März A, Schumacher W, Rösch P, Popp J (2011) Towards a fast, high specific and reliable discrimination of bacteria on strain level by means of SERS in a microfluidic device. Lab Chip 11:1013-1021

118. Newell DG, Koopmans M, Verhoef L, Duizer E, Aidara-Kane A, Sprong H, Opsteegh M, Langelaar M, Threfall J, Scheutz F, van der Giessen J (2010) Food-borne diseases-the challenges of 20 years ago still persist while new ones continue to emerge. Int $\mathrm{J}$ Food Microbiol 139:S3-S15

119. Neethirajan S, Ahmed SR, Chand R, Buozis J, Nagy É (2017) Recent advances in biosensor development for foodborne virus detection. Nanotheranostics 1:272-295

120. Yekta R, Vahid-Dastjerdi L, Norouzbeigi S, Mortazavian AM (2020) Food products as potential carriers of SARS-CoV-2. Food Control 107754

121. Todd EC, Grieg JD (2015) Viruses of foodborne origin: a review. Virus Adaptation and Treatment 7:25-45

122. Todd EC, Greig JD, Bartleson CA, Michaels BS (2008) Outbreaks where food workers have been implicated in the spread of foodborne disease. Part 4. Infective doses and pathogen carriage. J Food Protect 71:2339-2373

123. Gleizes O, Desselberger U, Tatochenko V, Rodrigo C, Salman N, Mezner Z, Giaquinto CM, Grimprel E (2006) Nosocomial rotavirus infection in European countries: a review of the epidemiology, severity and economic burden of hospital-acquired rotavirus disease. Pediatr Infect Dis J 25:S12-S21
124. Fan C, Hu Z, Riley LK, Purdy GA, Mustapha A, Lin M (2010) Detecting food- and waterborne viruses by surface-enhanced Raman spectroscopy. J Food Sci 7:M302-M307

125. Achadu OJ, Abe F, Suzuki T, Park EY (2020) Molybdenum trioxide nanocubes aligned on a graphene oxide substrate for the detection of norovirus by surface-enhanced Raman scattering. ACS Appl Mater Interfaces 12:43522-43534

126. Driskell JD, Zhu Y, Kirkwood CD, Zhao Y, Dluhy RA, Tripp RA (2010) Rapid and sensitive detection of rotavirus molecular signatures using surface enhanced Raman spectroscopy. PLoS One 5:e10222

127. Fan Z, Yust B, Nellore BP, Sinha SS, Kanchanapally R, Crouch RA, Pramanik A, Chavva SR, Sardar D, Ray PC (2014) Accurate identification and selective removal of rotavirus using a plasmonic-magnetic 3D graphene oxide architecture. J Phys Chem Lett 5:3216-3221

128. Shanmukh S, Jones L, Zhao YP, Driskell JD, Tripp RA, Dluhy RA (2008) Identification and classification of respiratory SynCytial virus (RSV) strains by surface-enhanced Raman spectroscopy and multivariate statistical techniques. Anal Bioanal Chem 390:1551-1555

129. Yeh YT, Gulino K, Zhang Y, Sabestien A, Chou TW, Zhou B, Lin Z, Albert I, Lu H, Swaminathan V, Ghedin E, Terrones M (2020) A rapid and label-free platform for virus capture and identification from clinical samples. Proc Natl Acad Sci USA 117:895-901

130. Kaminska A, Witkowska E, Winkler K, Dziecielewski I, Weyher JL, Waluk J (2015) Detection of hepatitis B virus antigen from human blood: SERS immunoassay in a microfluidic system. Biosens Bioelectron 66:461-467

131. Sun Y, Xu L, Zhang F, Song Z, Hu Y, Ji Y, Shen J, Li B, Lu H, Yang H (2017) A promising magnetic SERS immunosensor for sensitive detection of avian influenza virus. Biosens Bioelectron 89:906-912

132. Wang C, Wang C, Wang X, Wang K, Zhu Y, Rong Z, Wang W, Xiao R, Wang S (2019) Magnetic SERS strip for sensitive and simultaneous detection of respiratory viruses. ACS Appl Mater Interfaces 11:19495-19505

133. Zong $\mathrm{C}, \mathrm{Xu}$ M, Xu LJ, Wei T, Ma X, Zheng XS, Hu R, Ren B (2018) Surface-enhanced Raman spectroscopy for bioanalysis: reliability and challenges. Chem Rev 118:4946-4980

134. McLintock A, Lee HJ, Wark AW (2013) Stabilized gold Nanorod-dye conjugates with controlled resonance coupling create bright surface-enhanced resonance Raman Nanotags. Phys Chem Chem Phys 15:18835-18843

135. Mosier-Boss P (2017) Review of SERS substrates for chemical sensing. Nanomaterials 7:142

136. Zhang Y, Zhao S, Zheng J, He L (2017) Surface-enhanced Raman spectroscopy (SERS) combined techniques for high-performance detection and characterization. TrAC - trends anal Chem. 90:1-13

137. Robinson AM, Harroun SG, Bergman J, Brosseau CL (2012) Portable electrochemical surface-enhanced Raman spectroscopy system for routine spectroelectrochemical analysis. Anal Chem 84:1760-1764

138. Lynk TP, Sit CS, Brosseau CL (2018) Electrochemical surfaceenhanced Raman spectroscopy as a platform for bacterial detection and identification. Anal Chem 90:12639-12646

139. McLeod KER, Lynk TP, Sit CS, Brosseau CL (2019) On the origin of electrochemical surface-enhanced Raman spectroscopy (EC-SERS) signals for bacterial samples: the importance of filtered control studies in the development of new bacterial screening platforms. Anal Methods 1:924-929

Publisher's note Springer Nature remains neutral with regard to jurisdictional claims in published maps and institutional affiliations. 